\title{
The ECORS-Truc Vert'08 nearshore field experiment: presentation of a three-dimensional morphologic system in a macro-tidal environment during consecutive extreme storm conditions
}

\author{
Nadia Senechal • Stéphane Abadie • Edith Gallagher • Jamie MacMahan • \\ Gerd Masselink • Hervé Michallet • Ad Reniers • Gerben Ruessink • Paul Russell • \\ Damien Sous • Ian Turner • Fabrice Ardhuin • Philippe Bonneton • Stéphane Bujan • \\ Sylvain Capo $\cdot$ Raphael Certain $\cdot$ Rodrigo Pedreros $\cdot$ Thierry Garlan
}

Received: 23 September 2010 / Accepted: 30 June 2011 / Published online: 2 September 2011

(C) Springer-Verlag 2011

\begin{abstract}
A large multi-institutional nearshore field experiment was conducted at Truc Vert, on the Atlantic coast of France in early 2008. Truc Vert'08 was designed to measure beach change on a long, sandy stretch of coast without engineering works with emphasis on large winter waves (offshore significant wave height up to $8 \mathrm{~m}$ ), a threedimensional morphology, and macro-tidal conditions. Near-
\end{abstract}

Responsible Editor: Franciscus Colijn

N. Senechal $(\bowtie) \cdot$ S. Capo

OASU-EPOC, Université Bordeaux I,

avenue des Facultés,

33405 Talence, France

e-mail: n.senechal@epoc.u-bordeaux1.fr

\section{S. Abadie}

LaSAGeC2, Université de Pau et des Pays de l'Adour,

1 allée du Parc Montaury,

64600 Anglet, France

E. Gallagher

Department of Biology, Franklin and Marshall College,

Lancaster, PA 17604-3003, USA

J. MacMahan

Oceanography Department, Naval Postgraduate School,

Monterey, CA 93943, USA

G. Masselink

School of Geography, University of Plymouth,

Plymouth PL4 8AA, UK

H. Michallet

LEGI, Grenoble-INP/UJF/CNRS,

BP 53, 38041 Grenoble cedex, France shore wave transformation, circulation and bathymetric changes involve coupled processes at many spatial and temporal scales thus implying the need to improve our knowledge for the full spectrum of scales to achieve a comprehensive view of the natural system. This experiment is unique when compared with existing experiments because of the simultaneous investigation of processes at different
A. Reniers

Rosenstiel School of Marine and Atmospheric Science,

University of Miami,

Miami, FL, USA

G. Ruessink

Department of Physical Geography, Faculty of Geosciences, Institute for Marine and Atmospheric research, Utrecht University, P.O. Box 80.115, 3508 TC Utrecht, the Netherlands

P. Russell

School of Earth, Ocean and Environmental Sciences,

University of Plymouth,

Plymouth PL4 8AA, UK

D. Sous

LSEET, Université de Toulon et du Var,

83957 La Garde, France

I. Turner

Water Research Laboratory, School of Civil and Environmental

Engineering, University of New South Wales,

Sydney, NSW 2052, Australia

F. Ardhuin · T. Garlan

SHOM, Océanographie/Recherche,

CS 92803,

29228 Brest cedex 2, France 
scales, both spatially (from ripples to sand banks) and temporally (from single swash events to several spring-neap tidal cycles, including a major storm event). The purpose of this paper is to provide background information on the experiment by providing detailed presentation of the instrument layout and snapshots of preliminary results.

Keywords Field experiment - Surf zone - Swash zone · Open barred beach · Rip currents · Morphodynamics

\section{Introduction}

Exploring nearshore morphodynamic and hydrodynamic processes has been a challenging task in the last two decades. Our understanding of physical processes has been significantly improved through the many field experiments conducted by researchers worldwide. Field observations are an important source of information to identify new processes, generate and test new hypotheses and ultimately improve prediction skills of nearshore evolution. Moreover, they provide the only possibility for studying hydrodynamic and sediment transport processes under natural conditions. Collecting field data remains a key objective in coastal research for many other reasons; it allows model calibration and validation, and it drives, informs and complements controlled laboratory experiments. Barred beaches have received great attention in the coastal morphodynamic literature thanks to short-duration ( $<$ weeks) field experiments (amongst many others, Thornton et al. 1996; Gallagher et al. 1998; Ruessink et al. 1998; Ruessink et al. 2001; MacMahan et al. 2005; Aagaard et al. 2005; Masselink et al. 2008; Bruneau et al. 2009), long-term (> years) observations (amongst others Ruessink and Kroon 1994; Plant et al. 2001; Van Enckevort and Ruessink 2003a, b; Ranasinghe et al. 2004; Turner et al. 2007; Quartel et al. 2007; Senechal et al. 2009), numerical

\author{
$\overline{\mathrm{P} . \text { Bonneton } \cdot \mathrm{S}}$. Bujan \\ OASU-EPOC, CNRS, \\ avenue des Facultés, \\ 33405 Talence, France \\ R. Certain \\ IMAGES, Université de Perpignan, \\ 52 avenue de Villeneuve, \\ 66860 Perpignan cedex, France \\ R. Pedreros \\ BRGM, \\ 3 avenue Claude Guillemin, BP 36009, 45060 Orléans cedex 2, \\ France
}

\author{
A. Reniers \\ Civil Engineering and Geosciences, Delft University of \\ Technology, \\ Delft, the Netherlands
}

modelling approaches (amongst others Reniers et al. 2004; Garnier et al. 2006; Hsu et al. 2006; Dronen and Deigaard 2007; Smit et al. 2008) and physical modelling approaches (e.g. Grasso et al. 2009; Castelle et al. 2010).

Many studies have shown that nearshore wave transformation, circulation and bathymetric changes involve coupled processes at many temporal and spatial scales (amongst others Symonds and Ranasinghe 2000; Plant et al. 2001; Feddersen et al. 2003; Coco and Murray 2007; Ruessink et al. 2007; Thornton et al. 2007) thus implying the need to improve our knowledge over the full spectrum of scales to achieve a comprehensive view of the natural system. As reported by Thornton et al. (2000), 'the properties of waves incident from deep water and the beach profile (large-scale properties) determine the overall characteristics (e.g. surf zone width) of nearshore waves and flows (intermediate-scale properties). However, small-scale processes control the turbulent dissipation of breaking waves, bottom boundary layer and bedform processes that determine the local sediment flux. Cross- and alongshore variations in waves, currents, and bottom slope cause spatial gradients in sediment fluxes resulting in large-scale, planform evolution (e.g. erosion or accretion). As the surf zone bathymetry evolves, so do nearshore waves and currents that depend strongly on this bathymetry.'

Over the past decades, the traditional focus in nearshore research was on the intermediate scale, i.e. the cross-shore profile approach in waves, currents, sediment transport mechanisms and morphological change (amongst many others, Gallagher et al. 1998; Masselink et al. 2008; Grasso et al. 2011). For example, many works have reported that sand transport was dominated by suspension in high-energy environments and that undertow and rip currents (intermediate scales) thus play an important role in sediment transport and beach erosion processes (amongst others Ruessink et al. 1998; Thornton et al. 2007). However, to understand and predict the cross-shore gradients in the sediment transport and hence beach changes, it is important to understand local sediment fluxes (i.e. small-scale processes). Field data indicate that bedforms and grain size are key parameters for predicting nearshore sediment transport. For example, a variety of bedforms results in a widely varying bed roughness, which is an important feedback factor for suspended sediment transport processes (amongst others Grasmeijer and Van Rijn 2001; Gallagher et al. 2003). Effects of ripples, surface-generated turbulence and bottom boundary layers, are crucial in understanding sediment transport.

However, even on relatively straight beaches, the assumption of alongshore uniformity does not necessarily hold. Field evidence indicates that even in the case of a simple straight uniform coast, 3D patterns of water and sediment fluxes are observed, e.g. longshore current oscillations known as shear instabilities (amongst others Oltman-Shay et al. 
1989; Dodd et al. 2000; Ruessink et al. 2001; Noyes et al. 2004) and transient rip currents (amongst others Symonds and Ranasinghe 2000; Johnson and Pattiaratchi 2004). Clearly, on beaches with bathymetric variations (e.g. rip channels), a single cross-shore profile does not suffice. Field examples are provided by morphologic control of surf zone circulation (amongst others Castelle et al. 2006; MacMahan et al. 2008; Bruneau et al. 2009). Holman and Bowen (1984), Bryan and Bowen (1996, 1998) and Bryan et al. (1998) (amongst others) provide examples of morphologic control of infragravity wave processes. Today, there is a real need to go through at least horizontal, 2-dimensional (2DH) approaches, thus including the large-scale domain.

Tidal effects are also poorly understood despite field experiments that have shown that tides can determine the type, intensity and duration of the wave processes operating on the cross-shore profile (Kroon and Masselink 2002; Price and Ruessink 2008). Tides can modulate hydrodynamic processes such as surf zone circulation (Thornton and Kim 1993; Castelle et al. 2006; Bruneau et al. 2009) and wave breaking and control surf and swash bar dynamics (Reichmüth and Anthony 2007). Tides (particularly in meso- to megatidal environments) are also a key parameter in dune erosion. They allow, under spring tide conditions and associated to storm surges, the swash zone to operate on the upper beach, including dunes or cliffs and thus generating strong erosion (Ruggiero et al. 2001; Ruz et al. 2009).

There can be no doubt that a better understanding of beach vulnerability to storms will be required over the coming decades, especially given the prospect that global warming may induce more intense storms that could have a catastrophic impact on our coastlines. On the whole, there is still a lack of understanding of nearshore morphodynamics during a single storm and the subsequent recovery period but also more generally a rapid succession of storm/ post-storm conditions. Most of the previous field experiments, including those that involved the collection of comprehensive data, have been conducted during low- to high-energy waves (offshore significant wave height $H_{\mathrm{s}}<$ $5 \mathrm{~m}$ ). One of the key questions is to investigate whether our knowledge of the hydrosedimentary processes occurring during calm to moderate wave conditions can be extrapolated to extremely energetic conditions or whether other processes take over. This question motivated the Truc Vert'08 nearshore experiment. In particular, one of the main goals of TV'08 was to collect detailed observations spanning the full range of space and time scales and thus allowing for future detailed analysis of various processes and possible relationships between the different scales. At the same time, there is also still a lack of understanding complex 3D morphologies in meso- to macro-tidal environments, even under moderate conditions. TV'08, by incorporating extreme storm waves (significant wave height up to $8 \mathrm{~m}$ in $20 \mathrm{~m}$ water depth), macro-tidal conditions and complex 3D morphology, will certainly allow new insights in nearshore processes and hit the monetary scientific discussion in coastal morphodynamics.

Because of its complexity, TV'08 implied numerous nearshore teams, each being in charge of a specific topic. The future merging of all the data should provide a synoptic view of the dynamic of these complex 3D morphologies under macro-tidal conditions and energetic to extremely energetic conditions. Table 1 lists the 19 organisations that participated, involving more than 120 scientists, engineers, technicians, military personnel and students. Figure 1 provides the main topics of interest at different temporal and spatial scales. Small-scale processes typically include processes occurring over one single 'swash' or 'wave' event, while intermediate-scale processes include processes occurring over many 'swash' and 'wave' events. Finally, large-scale processes include processes occurring over several tides.

The purpose of this paper is to give an overview of the field experiment by providing the general settings including offshore conditions and a review of morphological evolution. Snapshots of the results are also presented. The paper is organised as follows: Section 2 presents the field area. Section 3 provides a detailed presentation of the instrument layout and associated measurements and presents the hydrodynamic conditions. Finally, Section 4 presents snapshots of results obtained on the small and intermediate scales with a review of large-scale morphology evolution.

\section{Field area}

\subsection{Regional setting}

Truc Vert beach (TVB) is situated on the southern part of the French Atlantic coast (Fig. 2a, b) and is typical of the relatively natural coast extending $100 \mathrm{~km}$ between the Gironde Estuary (90 km to the north) and the Arcachon inlet (10 km to the south). This sandy coast is almost N-Sorientated and bordered by high aeolian foredunes. TVB is situated far from human infrastructure, thereby allowing detailed analysis of natural processes to be obtained on a non-engineered coast. The sediment consists primarily of medium-grained quartz sand with a median diameter of about $0.35 \mathrm{~mm}$ (Lorin and Viguier 1987). During Truc Vert'08, however, variations in median diameter ranging from 0.30 to $0.55 \mathrm{~mm}$ were observed both cross-shore and alongshore (Gallagher et al. 2011).

\subsection{Truc Vert beach large-scale morphodynamics}

TVB is low sandy coast with beach face slopes varying between 0.03 under high energetic conditions and 0.06 
Table 1 Participating organisations during the ECORS-Truc Vert'08 field experiment
ECORS-Truc Vert'08 participating organisations

\begin{tabular}{lll}
\hline Universities & 1 & University of Bordeaux (EPOC, France) \\
& 2 & University of Miami (USA) \\
3 & University of New South Wales (Australia) \\
4 & University de Pau et des Pays de l'Adour (LaSAGeC ${ }^{2}$, France) \\
5 & University of Perpignan (IMAGES, France) \\
& 7 & University of Plymouth (UK) \\
& 8 & University of Toulon et du Var (LSEET, France) \\
& 9 & Delft University of Technology (the Netherlands) \\
& 10 & Franklin and Marshall College (USA) \\
& 11 & Institut National Polytechnique de Grenoble (LEGI, France) \\
12 & Naval Postgraduate School (NPS, USA) \\
Agencies & 13 & French navy (SHOM, France) \\
& 14 & Bureau de Recherche Géologique et Minière (BRGM, France) \\
& 15 & Centre national de Recherche Scientifique (includes EPOC, LSEET, LEGI, France) \\
& 16 & National Institute of Water and Atmospheric Research (NIWA, New Zealand) \\
& 17 & CRS/MNS (France) \\
18 & IMARTEC (France) \\
& 19 & RDI Teledyne \\
\hline
\end{tabular}

under moderate conditions. TVB exhibits complex 3D and highly dynamic morphologies commonly involving two distinct sandbar systems. The inner bar, generally situated in the lower inter-tidal domain, can evolve through all the morphological states within the intermediate classification (see Wright and Short 1984; Masselink and Short 1993) and usually exhibits a transverse bar and rip morphology
(Senechal et al. 2009) that can evolve into a low-tide terrace with a mean wavelength of $400 \mathrm{~m}$ after long periods (at least 10 days) of fair weather conditions (De Melo Apoluceno et al. 2002; Castelle et al. 2007). The outer-bar system, situated about $800 \mathrm{~m}$ offshore of the high-tide shoreline in water depths less than $10 \mathrm{~m}$ at high tide, exhibits persistent crescentic patterns with a narrow range
Fig. 1 Summarize of the different observed processes during the Truc Vert'08 nearshore experiment

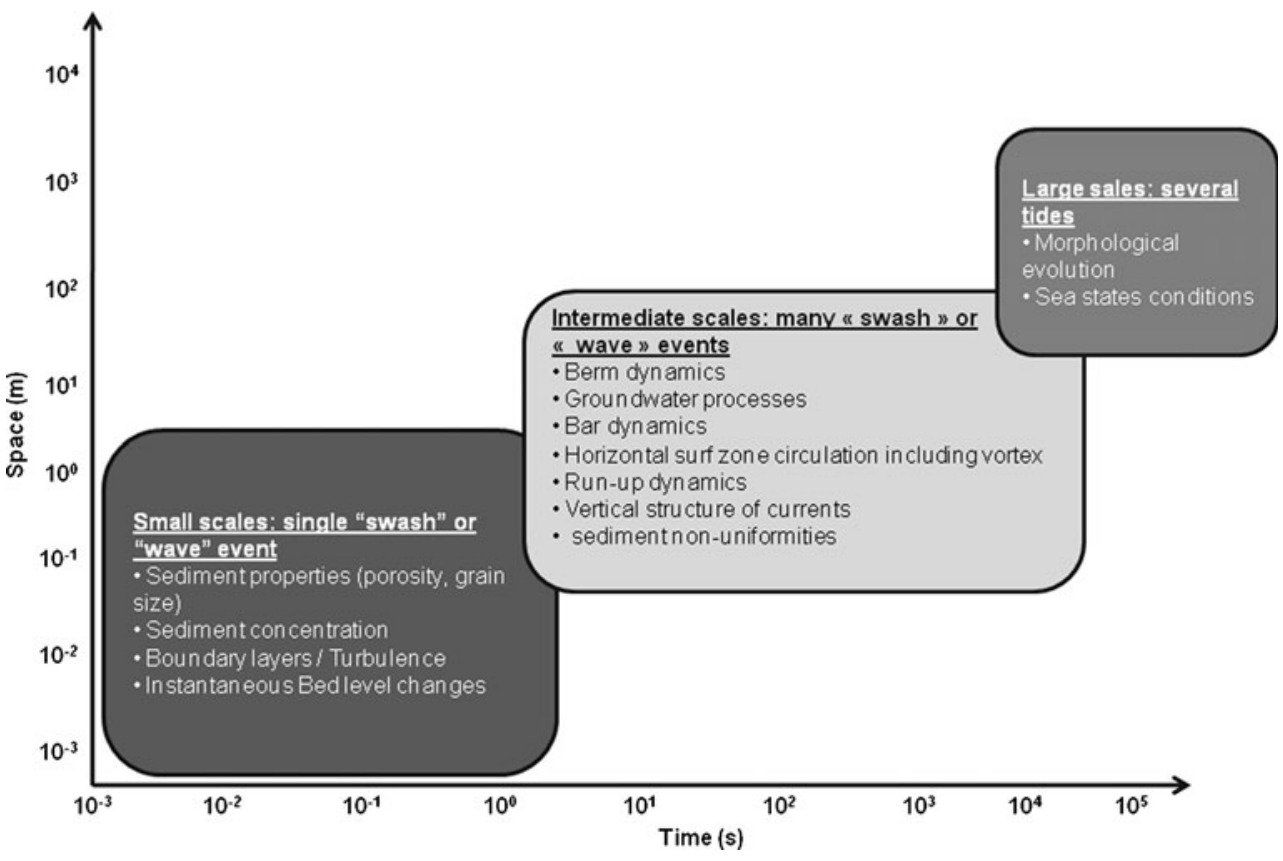


Fig. 2 Field area location a on the French Atlantic coastline b between the Gironde estuary and the Arcachon lagoon. c Beach configuration and general instrument deployment: remote sensing data 2 weeks previous to the field experiment. Outer crescentic bars are welldeveloped, the red rectangle corresponds to the inter-tidal area of instrument deployment (see Fig. 5 for the details), the white circles represent the wave/ current profilers deployed in the subtidal area and the two black lines represent the limit of video coverage
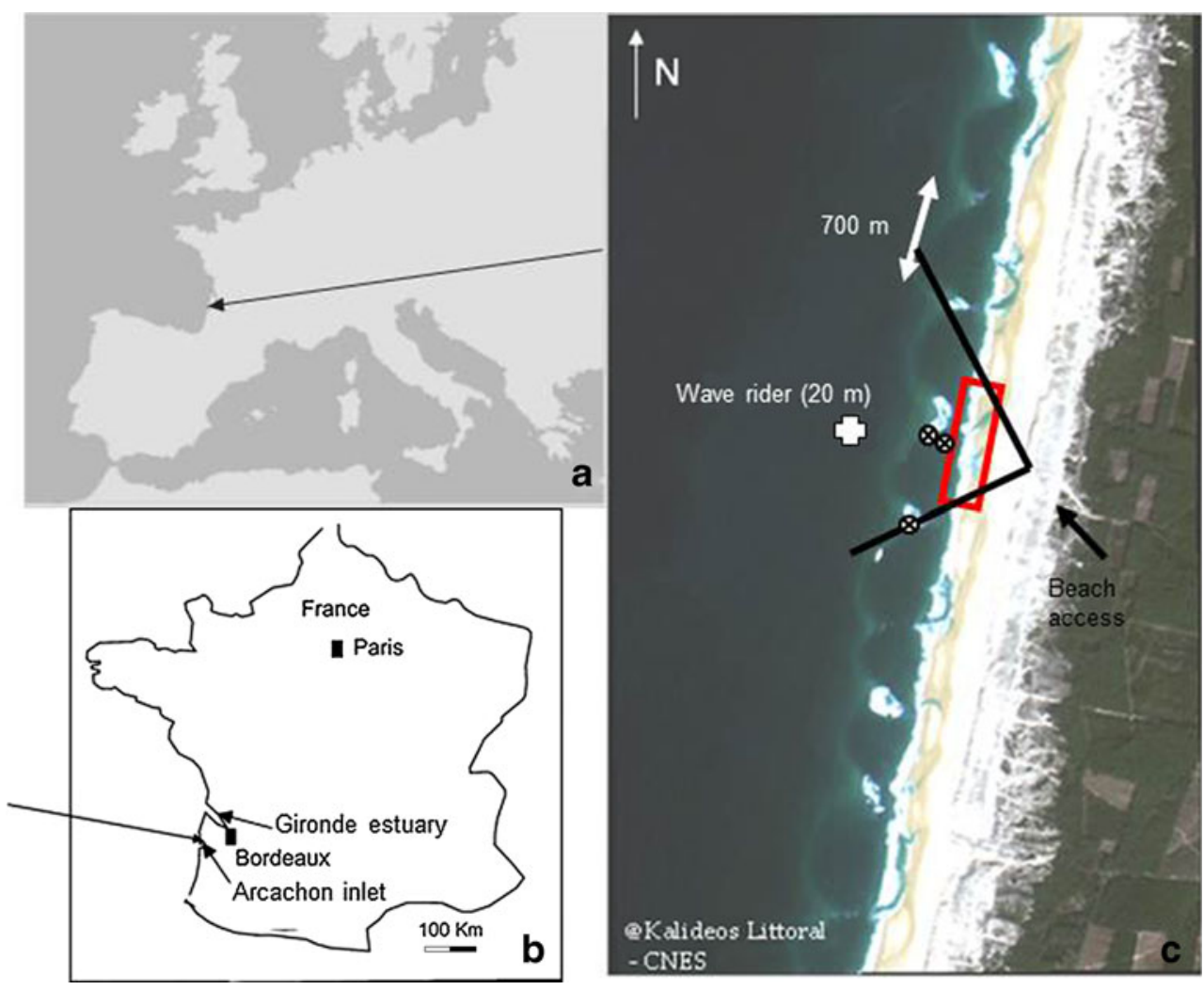

of wavelengths (individual shapes vary from symmetric to asymmetric, Castelle et al. 2007) of about $700 \mathrm{~m}$ (Lafon et al. 2004). Various aerial photographs and visual observations suggest that a 10 -year storm may be required to straighten the outer bar (Castelle et al. 2007).

\subsection{Truc Vert beach hydrodynamic setting}

TVB experiences an annual mean spring tide range of $3.7 \mathrm{~m}$. Tidal currents in the nearshore are essentially absent. The wave climate is moderate with an annual mean significant wave height of $1.4 \mathrm{~m}$ and a mean period around $6.5 \mathrm{~s}$, but a strong seasonal dependence is also evident (waves are higher in winter than in summer, see Butel et al. 2002 for a wave classification on the Aquitanian coast). During storm conditions, maximum offshore wave heights can reach up to $14 \mathrm{~m}$ in $20 \mathrm{~m}$ depth. Because of the presence of the subtidal bar, situated at about $800 \mathrm{~m}$ from the shoreline, the surf zone extends several hundred of metres during storm conditions and inshore significant wave heights are depth-limited generally less than $3 \mathrm{~m}$, even during spring high tides.

TVB is an interesting and challenging study site because of its complexity. Many data sets were collected at TVB over the last decade (Senechal et al. 2001, 2002, 2004; Castelle et al. 2006; Masselink et al. 2008), but none covered detailed observations of hydrodynamic processes and morphological response over a broad range of scales and conditions. The observations were also limited to the inter- tidal morphology with no continuous observations of the subtidal morphology. Furthermore, previous observations at TVB were collected under relatively mild storm conditions as offshore significant wave heights never exceeded $4 \mathrm{~m}$.

\section{General layout of the field experiment}

Truc Vert'08 was conducted during winter 2008. Sensor deployment in the inter-tidal area was from 3 March to 6 April. Most of the sensors presented in this section were deployed during the entire period but owing to very intense conditions, some of them were damaged, thus reducing their sampling period. Two weeks before the beginning of the experiment, bathymetric surveys were performed by the French Hydrographic Service (SHOM) together with topographic surveys and high-resolution remote sensing data acquisition (Fig. 2c). This step was essential to specify the exact position of the experiment site which should cover the 3D patterns in the inner and outer sandbars. In particular, this was critical to determine the area of daily topographic surveys to scale to the typical size of the observed bar systems. The selected area, extended $900 \mathrm{~m}$ in the alongshore, included one complete subtidal bar with two well-developed horns (Fig. 2c) and two to three rip channels and shoals on the complex inner bar. The experiment required installing a field camp on the higher part of the beach to provide power for instruments, storage 
and office space for computing and instrument control, internet access and GPS time as TVB is far from any human infrastructure.

\subsection{Offshore wave and tide conditions during Truc Vert'08}

Sea state during the experiment was measured with two directional Mark III Datawell waverider buoys anchored in 20 and $50 \mathrm{~m}$ depth. The waverider buoy anchored in $50 \mathrm{~m}$ was situated about 10 miles south west of the field area, and the waverider buoy anchored in $20 \mathrm{~m}$ was situated directly in front of the field area, about $1.5 \mathrm{~km}$ from the shore (Fig. 2c).

Figure 3 illustrates the offshore wave and tidal conditions as measured by waverider buoys anchored in $20 \mathrm{~m}$ water depth. Waves ranged from small swells with significant heights $\left(H_{\mathrm{s}}\right)$ less than $2 \mathrm{~m}$ and peak periods $\left(T_{\mathrm{p}}\right)$ of 12 to $18 \mathrm{~s}$, to heavy seas with maximum $H_{\mathrm{s}}$ of $8.1 \mathrm{~m}$, in the night from March 10 to March 11, associated with a peak period of 16 to $18 \mathrm{~s}$ as the wave height decreased slowly on March 11. This event (hereafter referred as the 8.1-m $H_{\mathrm{s}}$ storm), considered as a major storm for this coast, coincided with spring tide conditions and large associated tidal amplitudes (around $4 \mathrm{~m}$ ) and was also characterised by a narrow frequency and directional band spectrum. The waves had an oblique northwesterly incidence (about $10^{\circ}$ ). Waves generated during a different storm on March $16\left(H_{\mathrm{s}}\right.$ up to $5 \mathrm{~m}$ and hereafter referred as the 5-m $H_{\mathrm{s}}$ storm) had a nearly normal incidence and coincided with neap tide conditions and small associated tidal amplitudes (around $2 \mathrm{~m}$ ). A less severe sea state episode from 21 to 31 March was associated with much more oblique northwesterly waves which approached the beach at up to $25^{\circ}$ (from the northwest). Overall, during the whole experiment, Truc Vert experienced very high-energy conditions compared to the typical winter wave climate (winter mean $H_{\mathrm{s}}=1.57 \mathrm{~m}$ and mean period around $7.5 \mathrm{~s}$, see Butel et al. 2002). In addition, there was an unusual succession of very energetic events $\left(H_{\mathrm{s}}>4 \mathrm{~m}\right)$ over a short period of time, while a succession of several $<3 \mathrm{~m}$ events is more representative for this stretch of coast during winter periods.

\subsection{Instrument layout}

Figure 4 provides an overview of the measured parameters to address the hydrosedimentary processes at the different temporal and spatial scales. Figure 5 provides an overview of the instrument layout in the inter-tidal area (red box in Fig. 2c). Local and small-scale processes, in particular in relation to boundary layer processes, were addressed trough different instruments (Section 3.2.1) deployed in the swash and inter-tidal surf zone. The large-scale morphologic evolution was essentially addressed using qualitative description of the parameters (Section 3.2.2). Finally, intermediate-scale processes, essentially surf zone circulation and spatial non-uniformities, were addressed using both Eulerian and Lagrangian approaches (Section 3.2.3).

\subsubsection{Small-scale observations}

To understand and predict the cross-shore gradients in the sediment transport and hence beach change, it is important to examine local sediment fluxes. Field data indicate that

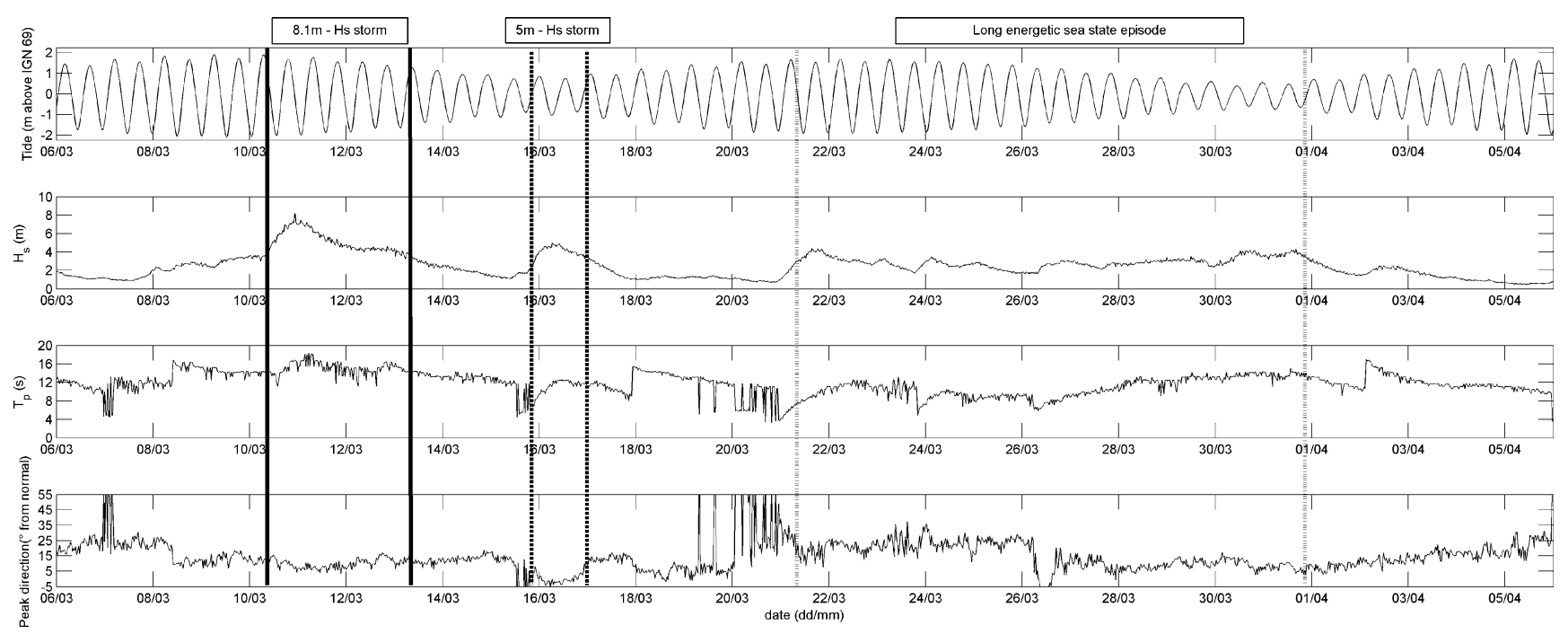

Fig. 3 Hydrodynamic conditions during the field experiment: a tides, b significant wave height measured by the waver rider buoys in $20 \mathrm{~m}$ water depth, c peak period and $\mathbf{d}$ direction, $280^{\circ}$ from normal incidence. The solid lines indicates the 8.1-m $H_{\mathrm{s}}$ storm, the black dotted lines the 5-m $H_{\mathrm{s}}$ storm and the grey doted lines the long energetic sea state period 
Fig. 4 Summarize of the measured parameters

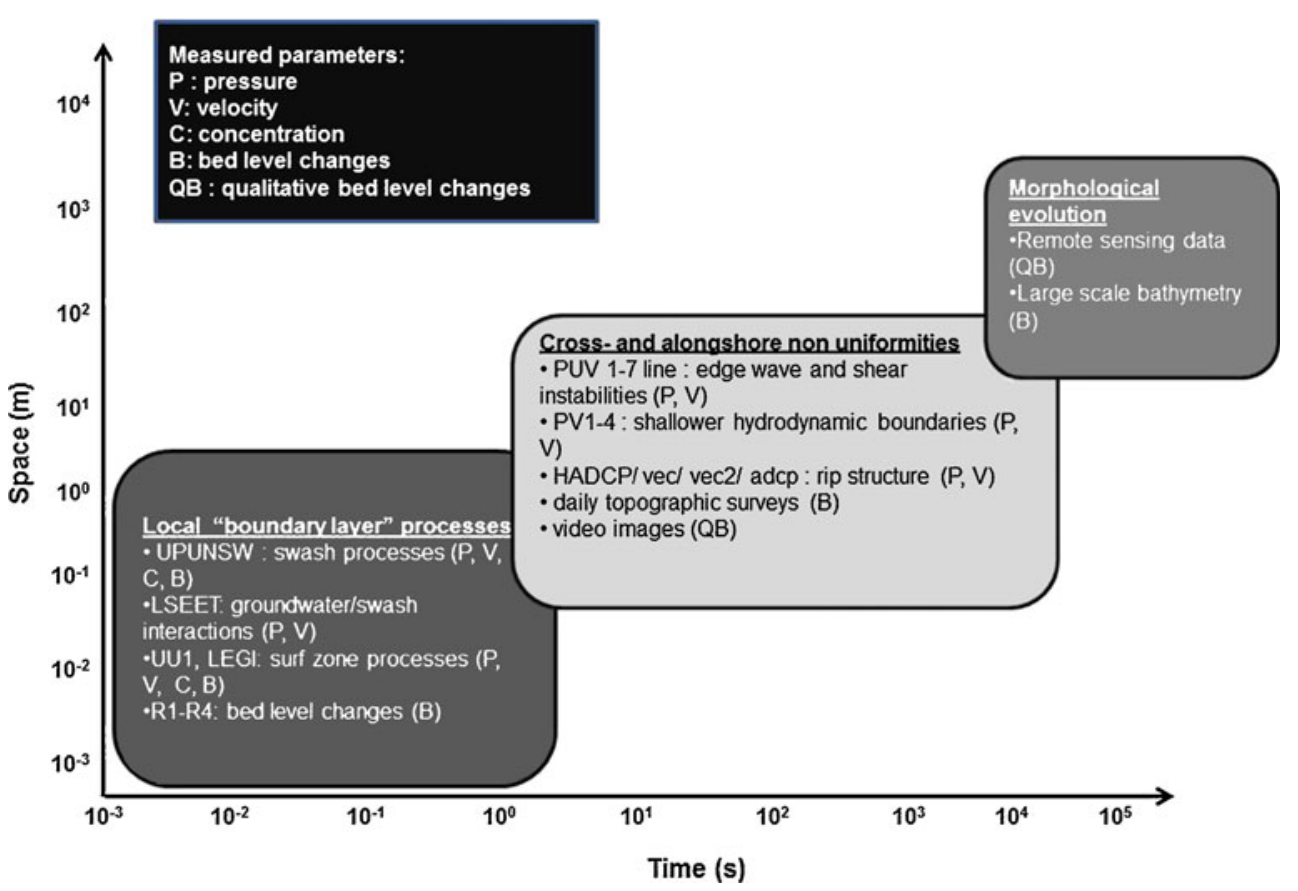

bedform and grain size are key parameters for nearshore sediment transport. For example, a variety of bedforms results in a widely varying bed roughness, which is an important feedback factor for suspended sediment transport processes in the presence of waves.

A major effort was made to measure the instantaneous local change in bed level. Various techniques to monitor bed-level changes exist (see Thomas and Ridd 2004 for a review), but they are usually designed and applied to relatively 'calm' environmental conditions. The new instruments presented below were used to follow the bed dynamics and estimate sediment fluxes in the swash zone and in the surf zone under higher-energy conditions (Saulter et al. 2003; Masselink et al. 2008; Berni et al. 2009; Arnaud et al. 2009; Emmanuel et al. 2009). These instruments include an array of ultrasonic bed-level sensors, optical backscatter stacks and electrical conductivity rods. These instruments were deployed at different positions in the inter-tidal area and thus only provide local information. Some instrumentations were also deployed along cross-shore transects. Future comparison of the small-scale measurements may allow to better evaluate both cross-shore and longshore non-uniformities and thus to explore the interactions between small-scale and intermediatescale processes.

Vertical structures of sediment concentrations under breaking waves and bed-level changes were studied at two locations with a single rig deployed in the inter-tidal area and thus experiencing mainly surf zone conditions. The first deployment was at the neap tide low-water level at the northern end of the study area (Fig. 5 referred as UU1). This rig was later moved to the mean-water-level immediately seaward of the UPUNSW (see below) scaffolding frame
(Fig. 5 referred as UU2). Sensors on this rig included three single-point, sideways-oriented 5-MHz Sontek ADVOcean probes (acoustic Doppler velocimeters) stacked in a $0.43-\mathrm{m}$ high vertical array to measure the vertical structure of turbulence fluctuations (Ruessink 2010), two electromagnetic flow meters to measure mean and oscillatory flows, one acoustic and seven optical backscatter sensors to measure sediment concentration within $1 \mathrm{~m}$ above the bed, a pressure gauge to measure sea-surface elevation and waves, a sand ripple profiling sonar to obtain bed-state information and acoustic sensors to measure bed levels. All instruments were cabled to a central logging unit that triggered all instruments each half-hour to ensure synchronous measurements. The ADVOcean probes and the triple-frequency (1, 2 and $4 \mathrm{MHz}$ ) acoustic backscatter sensor (ABS) sampled for $24 \mathrm{~min}$ and $40 \mathrm{~s}$ each half-hour at $10 \mathrm{~Hz}$. The downwardlooking ABS sampled the water column and bed with at 5-mm vertical bin resolution. The $2-\mathrm{MHz}$ ripple profiler scanned a cross-shore profile five times during the approximately $5 \mathrm{~min}$ that the ADVOcean probes and the ABS were not taking measurements (so the acoustic signals would not interfere). All other instruments sampled continuously at $4 \mathrm{~Hz}$. The logger's internal clock was time-synced to a GPS clock at its first deployment and deviated by less than $1 \mathrm{~s}$ from a GPS clock after 4 weeks.

Another frame (Fig. 6) was deployed with sensors to measure boundary layer flows and sediment concentration. This second rig was deployed in the inter-tidal zone as shown in Fig. 5 (referred to as LEGI) and $100 \mathrm{~m}$ south of that position in April. The acoustic Doppler velocimeter (ADVP) measures the three velocity components every $3 \mathrm{~mm}$ over a $30-\mathrm{cm}$ vertical profile (Hurther and Lemmin 


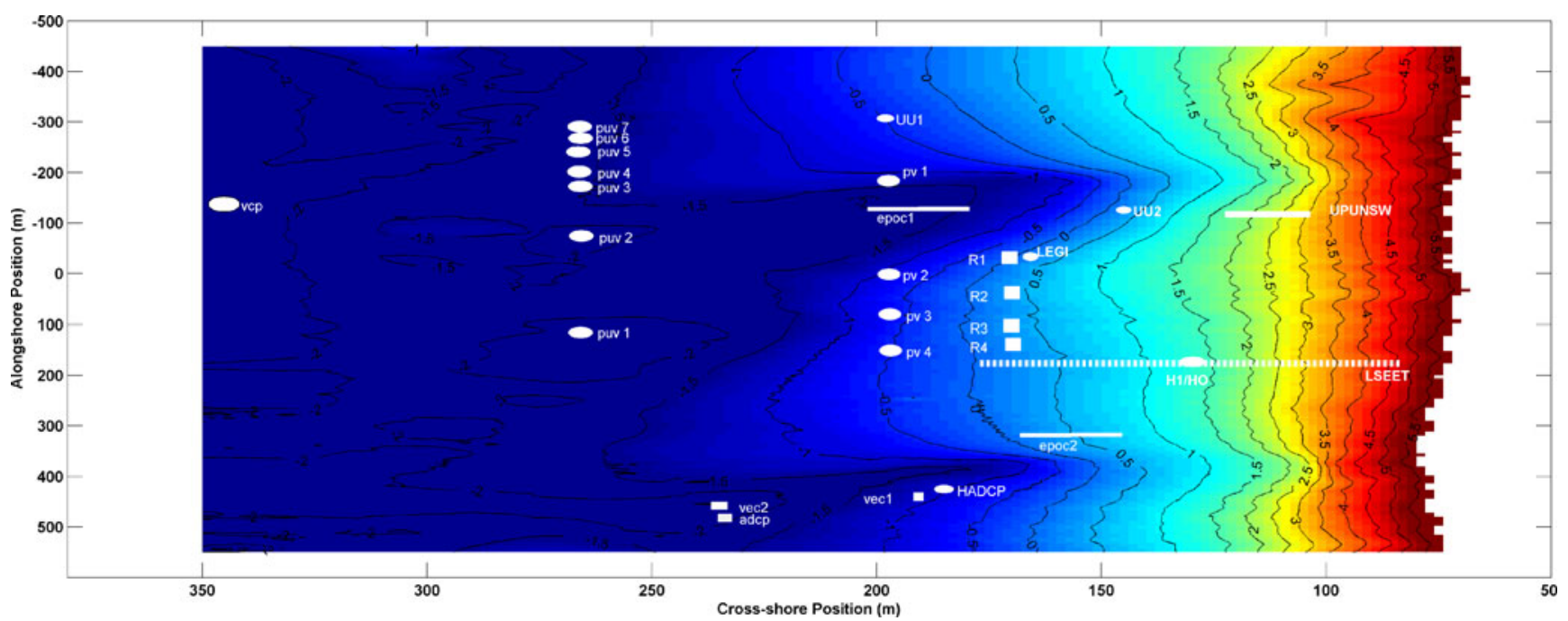

Fig. 5 Sensor deployment in the inter-tidal area. The topography corresponds to March 8 . See text for explanations. The cross-shore scale is expanded (factor 3 ) on regard of the longshore scale

2001; Mignot et al. 2009). The analysis of the backscattered acoustic intensity is used here for estimating the bed elevation (Berni et al. 2009). In addition, a set of optical fibre sensors was designed to measure the state of the medium at different elevations across the water/bed interface. Sensors located $5 \mathrm{~cm}$ apart detect (from the backscattering of light) whether a fibre tip is inside the soil, in the water layer or in a sediment suspension. A third set of instruments Druck PDCR 4030 pressure sensors were fixed every $20 \mathrm{~cm}$ on a beam embedded in the soil. They were used for measuring the pressure transmission in the soil and possible liquefaction events due to vertical pressure gradients (Michallet et al. 2009). Only the upper sensor is used here for determining the water level.

Previous instruments gave detailed information of sedimentary processes in the water column and in the sediment but due to their size and weight could not be moved easily over the area and as a result the detailed information was provided only over a restricted area. To make a more moveable and versatile bed-level sensor, straight rods, with 32 electrical conductivity sensors distributed every $5 \mathrm{~cm}$, were built for Truc Vert'08 (Fig. 6, UPPA). Each sensor on the rod measures the electrical conductivity of the surrounding medium in a local volume at the frequency of $10 \mathrm{~Hz}$ (see Arnaud et al. 2009 for a more detailed description of the instrument). After data post-processing, the bed elevation relative to the rod is deduced. Results were obtained as long as the surrounding sediments were wet. The surface of the water also can be obtained if it intersects the rod. After an initial trial period during which the rods were deployed one at a time, an array of several rods was deployed in two configurations. From March 20 to 29 (offshore $H_{\mathrm{s}}=3 \mathrm{~m}$ ), several rods were deployed in an alongshore array (R1 to R4 in Fig. 5) This instrument frame was also used to investigate the bed erosion processes due to phase lag in pressure transmission in the soil and induced water exfiltration (Butt et al. 2001; Mory et al. 2007) at around mean sea level. The rods all worked successfully during a few tides. A more complete and homogeneous dataset was obtained from the April 3 to 8 , in a cross-shore deployment involving five rods (not shown in Fig. 5, Arnaud et al. 2009).

A large scaffold frame (28 m long and $4 \mathrm{~m}$ wide) was constructed on the upper beach around the mean high-tide level and jetted into the sand to serve as a platform for the cross-shore array of instrumentation to measure swash zone sediment dynamics and bed levels (Figs. 7 and 5, referred

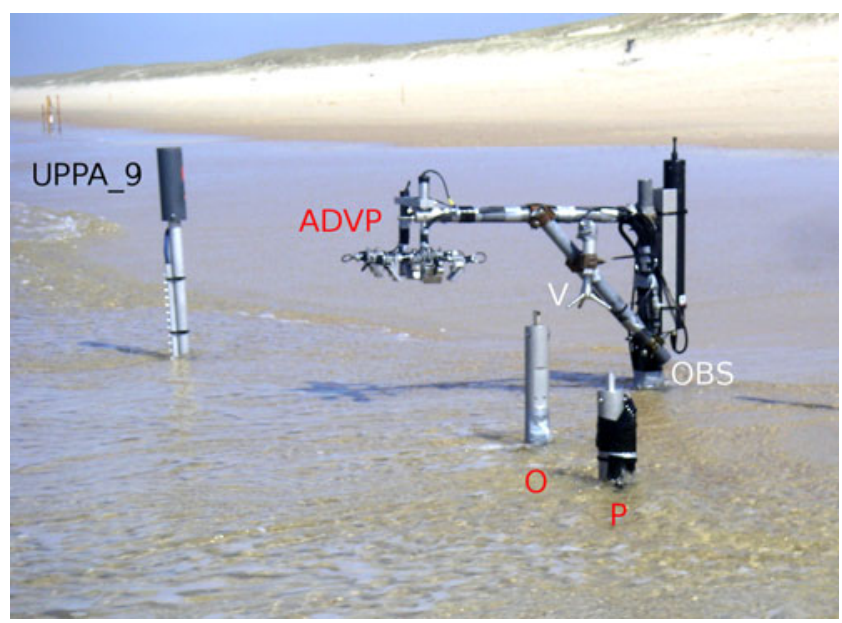

Fig. 6 Photograph of the instrument used to measure real time sand level changes in swash and surf zone areas (UPPA and LEGI). Scaffolding structure supporting the acoustic Doppler velocimeter profiler, a Nortek Vector and OBS3+ sensors; 1.5 and $2.2 \mathrm{~m}$ south the beams of $(O)$ optical and pressure sensors; one resistive rod system 2 m north (UPPA_9) 
Fig. 7 Beach profile at the start of the field experiment with instruments locations and photograph showing the scaffolding structure used for mounting the instruments (Russell et al. 2009). The swash instrument rig depicted by the open circle represents the main instrument rig with the vertical array of current meters and suspended sediment sensors
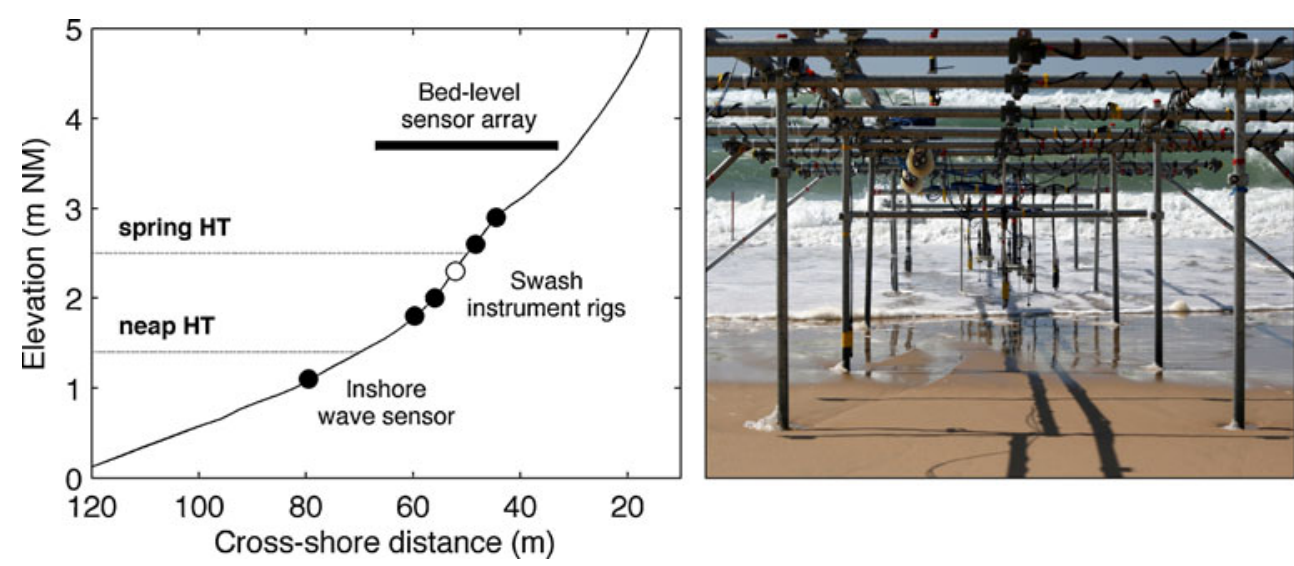

as UPUNSW). Measurements were made from March 19 to April 4 and over 33 tidal cycles. Swash velocities, water depths and suspended sediment concentrations were measured at five locations along the main cross-shore transect in the swash zone using instruments described extensively by Masselink et al. (2008). Swash flow velocities were measured using mini-electromagnetic current meters that were carefully positioned and regularly adjusted to enable flow measurements to be taken at $3 \mathrm{~cm}$ above the bed. At the central swash rig, swash flows were also measured at 6 , 10 and $14 \mathrm{~cm}$ from the bed to obtain information on the vertical velocity profile. The main innovative aspect of the swash research was the measurement of high-frequency bed-level data using an array of 45 ultrasonic bed-level sensors (BLS). The sensors are described by Turner et al. $(2008,2009)$ and were mounted approximately $1 \mathrm{~m}$ above the bed and arranged in three cross-shore lines of 15 sensors with a spacing of $1.9 \mathrm{~m}$. When mounted perpendicular to the bed, the bed-level sensors make non-intrusive measurements of the vertical distance to the closest target (bed level when the bed is dry and swash height when the bed is submerged) based on the return time of flight of a reflected signal. All instruments were cabled to the shore and data were recorded at $4 \mathrm{~Hz}$ using a bank of laptop computers that were time-synced to a GPS clock.

At the same time, a cross-shore array extending from the berm to the low-tide mark (spring conditions) was also deployed to study interaction between groundwater and swash dynamics (Fig. 5, referred as LSEET). The array consisted of a line of single pressure sensors alternately immersed and emerged during the tide cycle. In addition, several steel bars (up to $2.5 \mathrm{~m}$ high) supporting two or three pressure sensors were buried in the sand in order to combine vertical and horizontal characterisation of the water surface for each side of the foreshore surface. All pressure sensors measure relative pressure in comparison with atmospheric pressure (use of vented cables) on a scale of $0-400$ or $0-800 \mathrm{mb}$, with a $0.1 \%$ accuracy. They were protected by a porous screen to prevent sediment from infiltrating and touching the sensor (see Turner and Nielsen 1997; Horn 2002). All instruments were cabled to two data loggers and linked to a network to allow direct synchronized data recording. The data were sampled at a $5.9-\mathrm{Hz}$ frequency. Because of the rapid morphological changes (see Section 4 below) and the numerous impacts of floating objects (tree trunks) on the steel bars, daily topographic surveys using a GPS were performed.

Small-scale processes control bottom boundary layer and bedform processes that determine the local sediment flux but cross- and alongshore variations cause spatial gradients in sediment fluxes resulting in large-scale, planform. There was thus a need to estimate these large-scale modifications in order to allow for possible future comparison of the measurements, which may allow a more synoptic picture of TVB.

\subsubsection{Intermediate-scale observations}

In the two previous sections, bottom boundary layer, bedform processes and sediment flux were determined locally, typically at small temporal scale ('swash' or 'wave' event), and the resulting morphological evolution was evaluated at large scales. This section aims at describing intermediate-scale variations in waves, currents and bottom slope, which cause spatial gradients in local sediment fluxes resulting in large-scale planform evolution (e.g. erosion or accretion). Due to very high-energy conditions during most of the field campaign, some of the sensors that were supposed to be deployed in the subtidal area over the outerbar system could not be installed. As a result, only two wave/vertical current profilers were deployed on the horn of the outer crescentic bar, and another was deployed offshore of the inner rip channel (Figs. 2c and 5, vcp).

Several single-point self-recording pressure and velocity sensors were also deployed on the upper beach face to determine wave transformation and conditions in the shallower areas (Fig. 5, referred as pv 1 to pv 4). The internal clocks of the instruments were regularly checked 
and time-synced to a GPS clock. One horizontal acoustic Doppler current profiler (HADCP; Fig. 5) was deployed for a few days in the feeder of one rip channel with an array of single-point acoustic Doppler velocimeters (vec1 and vec2, Fig. 5) and an ADCP, all located in the rip channel vicinity (Fig. 5). The HADCP measurements characterise velocities by the Doppler principle along three beams on a horizontal plane.

A combination of Eulerian and Lagrangian instrumentation was deployed in the inter-tidal surf zone to describe the mean and surf zone-scale fluctuating motions at temporal scales $>20$ s. A synchronous, $15-\mathrm{Hz}$ coherent seven-element alongshore-lagged array of co-located pressure and horizontal digital electromagnetic velocity sensors mounted to pipes jetted along the inner bar was deployed to record the alongshore wave numbers and frequencies for inter-tidal surf zone infragravity (IG) motions and very low-frequency motions (VLF; discussed in Section 4.3.2). The instruments were located approximately $35 \mathrm{~cm}$ from the seabed. All instruments were cabled to the shore and time-synced to an onshore GPS clock (Fig. 5, referred as puv 1 to puv 7).

Efforts have also been made to define a new method to measure and analyse the spatial structure of VLF motions. Strong correlations between the cross-shore wave celerity time variations, estimated from the time lag between two external pressure sensors (Fig. 5, epoc1, epoc2, Tissier et al. 2009) and the VLF cross-shore current oscillations (line epoc1), were observed. This phenomenon can be used as a proxy to analyse the spatial structure of VLF motions from high-frequency wave celerity video observations.

GPS-equipped surf zone drifters were deployed on eight different days over a range of wave and tidal conditions to capture circulation patterns and particle pathways (Davis 1991; Schmidt et al. 2005; MacMahan et al. 2010a amongst others), dispersion and diffusion (Spydell et al. 2007; Brown et al. 2009), synoptic flow field and exchange rate between the surf zone and inner shelf (MacMahan et al. 2010a; Reniers et al. 2009, 2010). Lagrangian observations associated with GPS-equipped drifters provided new perspectives on surf-zone behaviour that cannot be measured with fixed Eulerian instruments (see Section 4.3.1). The GPSequipped surf zone drifters were designed to minimize surfing in the breaking waves and were shown to closely follow simultaneously deployed dye (see MacMahan et al. 2008 for more drifter details). Depending on field conditions, the number of drifters deployed ranged from 14 to 22 and were deployed in clusters ranging from four to 16 drifters.

Spatial and temporal variability of grain size were measured in the inter-tidal area. To measure bed surface grain size, a digital imaging system (DIS) consisting of a Nikon D70 camera with a macro lens and magnifiers mounted in an underwater housing was used (Gallagher et al., submitted for publication). The DIS is lightweight and easy to handle by a person walking and its position was determined at TVB by a small GPS device worn by the person (accurate to about $10 \mathrm{~cm}$ ). The digital images are analysed using an autocorrelation technique following Rubin (2004). In this way, spatial maps of grain size were made of the study region. Sediment was also collected three times at low tide at 357 positions equally distributed over the area with a cross-shore and alongshore resolution of $25 \mathrm{~m}$, thus covering an alongshore distance of $500 \mathrm{~m}$ and a cross-shore distance of $400 \mathrm{~m}$. The sampling positions were the same for the three surveys. Samples were analysed using sieving and laser methods. Apart from the notable works by Guillén and Hoekstra (1996), 1997) carried out during a shoreface nourishment field experiment (Nourtec project), these can be considered as one of the highestresolution ( $20-\mathrm{m}$ spacing) measurements of grain size variability across a large 2DH study region (up to 400 by $500 \mathrm{~m}$ ) under natural conditions. Daily measurements of sediment porosity using coring techniques on two crossshore lines were also performed.

\subsubsection{Large-scale observations}

At large scale, the resulting morphological evolution was evaluated by both in situ measurements and remote sensing. Bathymetry surveys were performed over a large area $(1 \mathrm{~km}$ alongshore by $0.5 \mathrm{~km}$ cross-shore), involving large vessels deployed by the French navy and on a smaller area $(0.4 \times$ $0.5 \mathrm{~km}$ ) using an instrument-equipped wave runner when wave conditions permitted. Daily topographic surveys of the inter-tidal area on a 900-m longshore stretch were performed with a GPS-equipped ATV in the dry areas or by a walking operator in moderate water depths. A full description of the collection and processing of these data can be found in Parisot et al. (2009). Remote sensing data consisted of large-scale, high spatial resolution satellite images (Dehouck et al. 2009) and a continuous collection of daylight 2-Hz video images (NIWA technology, Almar et al. 2010) with two cameras deployed on the foredune. Tenminute averages of the instantaneous video images were used for daily tracking of the positions and shapes of the subtidal (outer) and inter-tidal (inner) bar systems throughout the experiment (see Almar et al. 2010). Attempts were also made to determine mean-water elevation and wave height using stereoscopic methods from the available video imagery.

\section{Results}

The aim of this section is to present some preliminary results from the field campaign to highlight the types and breadth of measurements that were made at different spatial and temporal scales. First, emphasis will be given to small- 
scale processes, presenting unique observations under both moderate conditions $\left(H_{\mathrm{s}}<2 \mathrm{~m}\right)$ and extremely energetic conditions ( $H_{\mathrm{s}}$ up to $8 \mathrm{~m}$ ). One of the key questions is to investigate whether our knowledge of the hydrosedimentary processes occurring during calm to moderate wave conditions can be extrapolated to extremely energetic conditions or whether other processes take over. Both single swash/wave events and resulting from several swash/waves events 1D cross-shore evolution will be presented. Then, a review of large-scale modifications in beach morphology will highlight that offshore conditions, resumed to a single event, are not the unique driver in the beach response. Spatial non-uniformities in small-scale hydrosedimentary processes and developments will not be presented in the present study because they need further analysis, but possible coupling effects between the nearshore circulation and the underlying morphology will be presented in the last subsections as preliminary intermediate-scale processes.

\subsection{Small-scale processes and associated 1D cross-shore evolution}

\subsubsection{Temporal bed form dynamics in the surf zone}

Figure 8 presents two examples of the electrical signal recorded by vertical rods (see Section 3.2.1). The graphs
Fig. 8 Time-dependent change in electrical resistivity along rod 1. Top panel: on March 26, $H_{\mathrm{mo}}=2.5 \mathrm{~m}$, rod located at MSL, bottom panel: on April 6, $H_{\mathrm{mo}}=1 \mathrm{~m}$, rod located $2.5 \mathrm{~m}$ above MSL
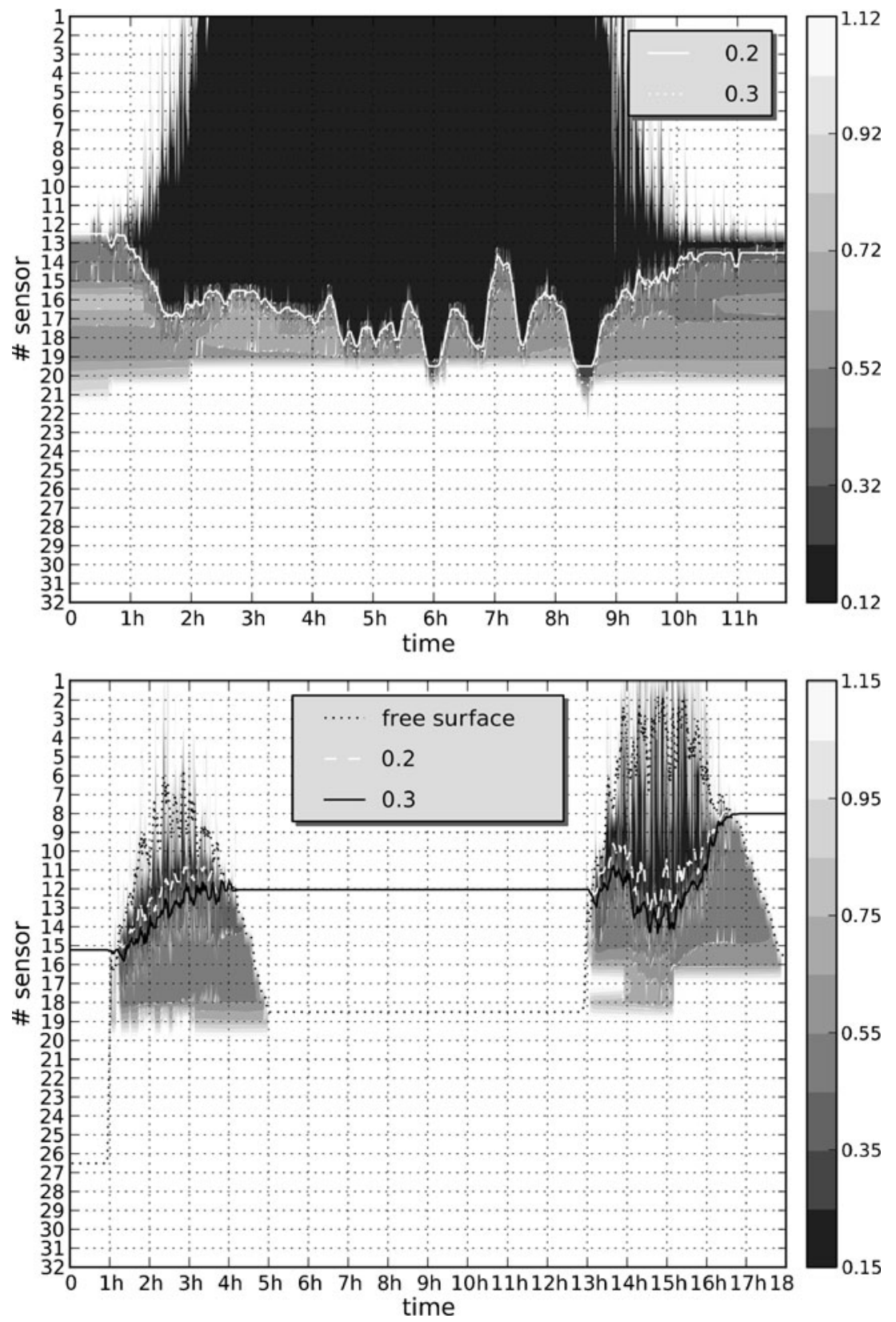
represent the time variation of vertical distribution (along the 32 sensors) of electrical resistivity (ohm metre) as interpolated contours. Following Arnaud et al. (2009), resistivity values up to $0.2 \Omega \mathrm{m}$ correspond to seawater, between 0.2 and 0.3 to sediment suspension or high porosity values and above $0.3 \Omega \mathrm{m}$ first to saturated sediment and then to air or dry sediment (for higher values). The data presented in the top panel were recorded on March 26. The rod was located approximately at mean sea level (MSL) and $H_{\mathrm{s}}$ increased from 2 to $3 \mathrm{~m}$ this day. The first waves reach the rod about $1 \mathrm{~h}$ after the start of recording. The gradual rise in sea level is associated with the upper limit of the dark surface. The sea bottom lies at the transition between dark and lighter areas. A moving average (5 min window) associated with a $0.3-\Omega \mathrm{m}$ resistivity value is plotted in white and assumed to be a good approximation of the seabed position as validated by several DGPS measurements at low tide. However, as the seabed under high-energy conditions may not be discontinuous but rather a concentration gradient, the $0.2-\Omega \mathrm{m}$ contour is added on the plot in order to show the limit of sea water. Examination of the $0.3-\Omega \mathrm{m}$ contour shows that the sand level initially decreases from sensor 13 at $t \sim 1 \mathrm{~h}$ to sensor 18 at about mid-tide $(t \sim 5.5 \mathrm{~h})$ which corresponds to an erosion of $15 \mathrm{~cm}$ and an erosion rate of $3.3 \mathrm{~cm} / \mathrm{h}$. The four oscillations of the sand level are attributed to megaripples propagation. These oscillations have a maximum amplitude of about $20 \mathrm{~cm}$ and an approximate period of $40 \mathrm{~min}$. Megaripples were also observed at location UU1 and UU2 (Fig. 5) at low spring tide level. And then finally, the sand level goes back to its initial value located around sensor 13 (deposition rate $13 \mathrm{~cm} / \mathrm{h}$ ).

At UU1, we succeeded in measuring bedform variability during the very high-wave energy period from March 7 to March 16, encompassing the 8.1-m $H_{\mathrm{s}}$ storm on March 11. The instantaneous location of the seabed was estimated as the location of the seabed echo in the ABS data. This echo was determined using a thresholding algorithm. Instantaneous bed-elevation series of the three transducers were highly similar (correlation coefficient squared generally exceeded 0.95). The example time series of bed elevation in Fig. 9 indicates that, similar to the observations in Fig. 8, the bed showed fluctuations on two distinct time scales. Firstly, the seabed oscillated with amplitudes less than about $0.2 \mathrm{~m}$ on a time scale of an hour or less. Secondly, the seabed increased or decreased slowly on a time scale of hours. To separate the two types of fluctuations, the instantaneous bed level estimated from the $1-\mathrm{MHz}$ transducer was low-pass filtered with a cutoff of 3 h (e.g. Fig. 9). The perturbations of the instantaneous ABS bed-level estimates from the low-pass estimates are believed to be temporal bedform dynamics. The standard deviation, $z_{\mathrm{rms}}$, of these perturbations, determined for each burst, fluctuated with the tide to reach maximum values of 0.05 to $0.1 \mathrm{~m}$ around high tide (Fig. 10a, b). This suggests (Gallagher et al. 2005) that bedform amplitudes were the largest at high tide. During low tide, when the rig was not submerged, no ripples were observed near the rig, implying that the swash acted to smooth the seabed completely. Values of $z_{\mathrm{rms}}$ were approximately time independent at $0.01-0.02 \mathrm{~m}$ during several tides during and following the storm on March 11, suggesting that only then the bed remained smooth (without bedforms) throughout. During these tides, the mobility number $\psi=\left\langle u^{2}+v^{2}\right\rangle /((s-1) g D)$, where $u$ and $v$ are the instantaneous cross-shore and alongshore velocity at the lowest $\mathrm{ADV}$, the angle brackets represent time averaging, $s=2.65$ is the specific gravity of quartz sand, $g=9.81 \mathrm{~m} / \mathrm{s}^{2}$ is gravitational acceleration and $D$ is the median grain diameter, exceeded $\approx 150-200$, compare Fig. 10c, a. Earlier field observations (e.g. Gallagher et al. 2005) also indicated $\psi \approx$ 150-200 to mark the transition from a rippled to a smooth bed. Interestingly, $\psi$ attained such high values because of the large infragravity motions (Fig. 10d, e) combined with large alongshore currents; during the peak of the storm, the crossshore root-mean-square (rms) infragravity velocity was about $0.8 \mathrm{~m} / \mathrm{s}$ (Fig. 10d), and the mean alongshore current was about $1 \mathrm{~m} / \mathrm{s}$ (Fig. 10e). The results indicate the potential importance of infragravity waves to erase bed forms during high-wave conditions.

Complete swaths of the sand ripple profiling sonar at UU1 were too infrequent to examine in detail spatial bedform characteristics and their relationship with the prevailing hydrodynamics. Observations beneath non-breaking waves indicate the presence of small-scale (heights of order $0.15 \mathrm{~m}$
Fig. 9 Instantaneous bed level (grey dots) with respect to mean sea level estimated from the 1-MHz ABS transducer at UU1 versus time during a single tide. The solid line is the low-pass series computed with a 3-h cutoff. Time 0 corresponds to March 9, 1030 UT

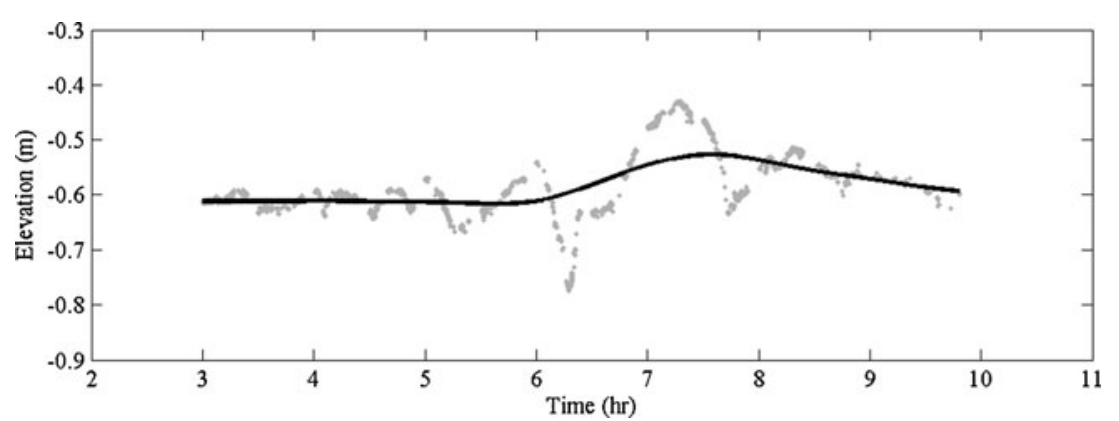


Fig. 10 Standard deviation $z_{\mathrm{rms}}$ of instantaneous bed level with respect to the low-pass bed-level series, $b$ water depth $h, c$ mobility number $\psi, d$ root-meansquare cross-shore velocity $u_{\text {rms }}$ of the (thick line) sea-swell and (thin line) infragravity band and $e$ mean cross-shore $\langle u\rangle$ and alongshore $\langle v\rangle$ velocity versus time at UU1

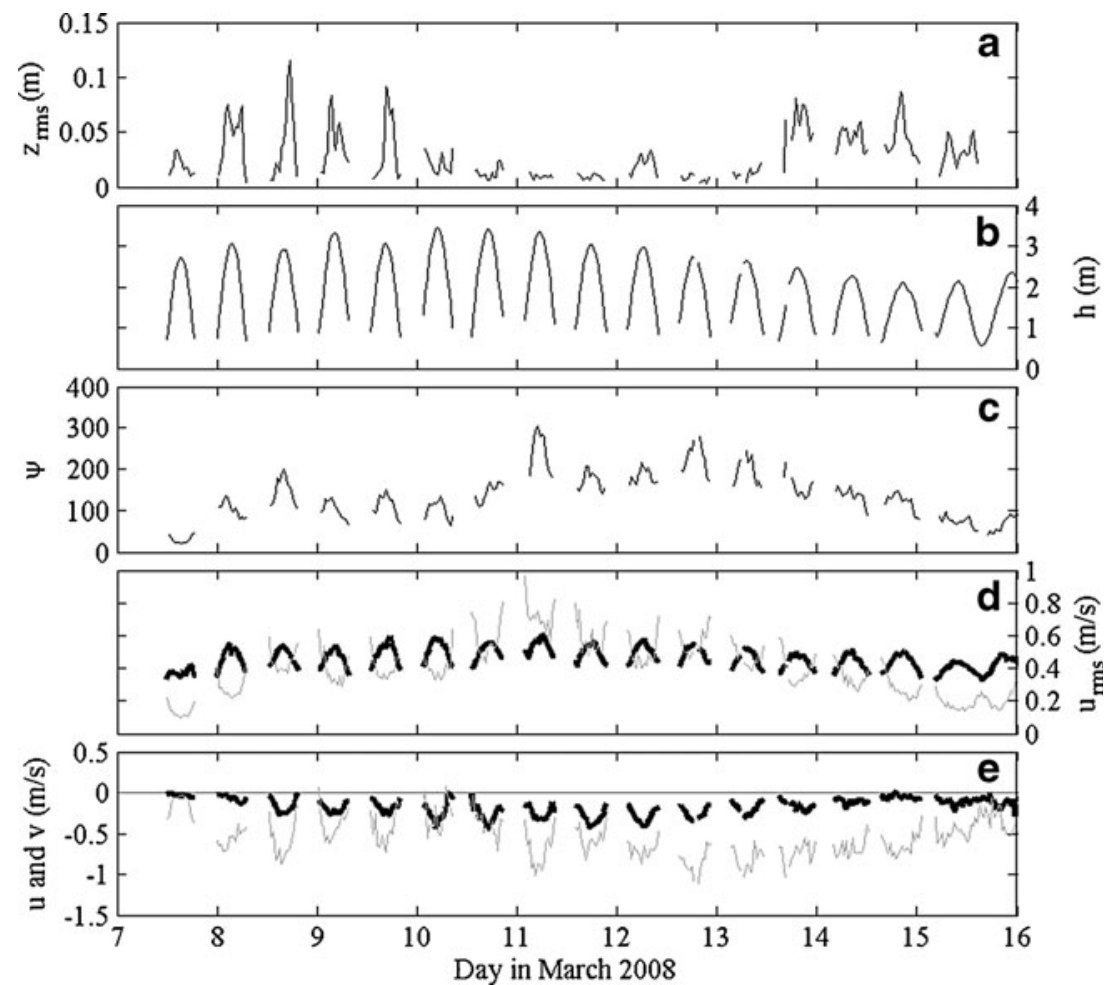

and cross-shore lengths of order $0.5 \mathrm{~m}$ ) wave-driven vortex ripples (Fig. 11a). Beneath breaking waves but with $\psi<150$, larger-scale (cross-shore lengths $1-1.5 \mathrm{~m}$ ) bedforms with rounded crests (Fig. 11b) or up to $\approx 0.4-\mathrm{m}$ deep pits (Fig. 11c) with a cross-shore length exceeding the cross-shore swath length, resembling megaripples (Ngusaru and Hay 2004), were most commonly observed. When $\psi>\approx 150$, the seabed was indeed without bedforms (Fig. 11d).

\subsubsection{Upper beach face hydromorphodynamics along a cross-shore transect}

An overview of the hydrodynamic conditions and the morphological development during the 16-day (33 tides) period, extending from March 19 to April 4, of the large scaffold (referred as UPUNSW in Fig. 5) is provided in Fig. 12a-c. The offshore significant wave height $H_{\mathrm{s}}$ was $2-$
Fig. 11 Representative examples of seabed configuration at UU1. a Small-scale wave-induced vortex ripples, March 7, 1355 UT; b larger-scale (with respect to a) ripples with rounded crests, March 15, 2055 UT; c a single pit, March 14, 0625 UT and d smooth bed (no bedforms), March 13, 0755 UT. $x=0$ is directly below the sonar; positive $x$ is offshore directed. The elevation $z$ is with respect to mean sea level. Note that the seabed is dipping (incorrectly) onshore because the sonar had no internal tilt sensor
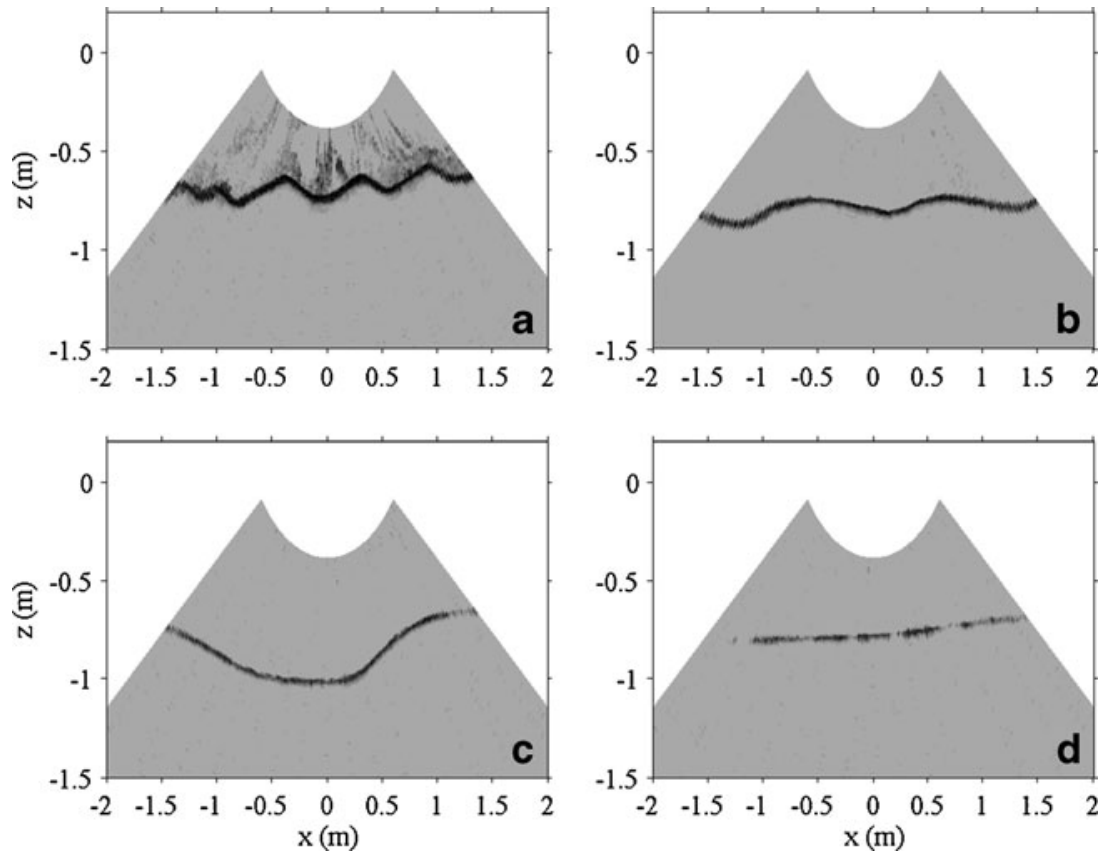

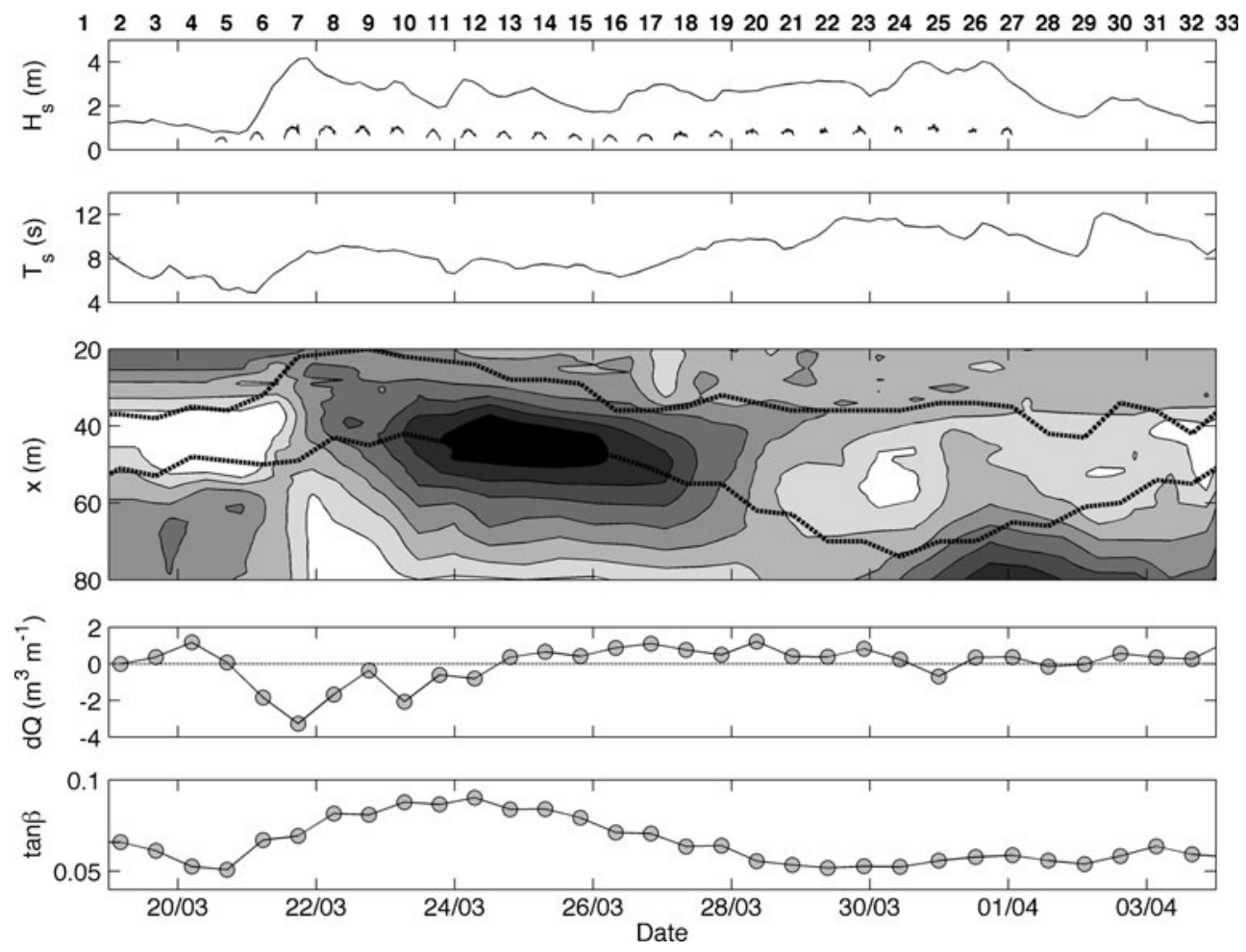

Fig. 12 Wave conditions and beach morphological change during the swash zone measurements from March 19 to April 4 (modified from Masselink et al., submitted for publication). From top to bottom: significant offshore (continuous line) and inshore (discontinuous line) wave height $H_{\mathrm{mo}}$, significant offshore wave period $T_{\mathrm{s}}$, change in bed level relative to the mean profile over the field experiment ( $x=$ crossshore distance from the base of the dunes), sediment volume change $\mathrm{d} Q$ over the high-tide swash zone and beach gradient $\tan \beta$ in the high-

$4 \mathrm{~m}$ during tides 6 to 31 (March 21 to April 3) and 1-2 m at the start and the end of the period (see also Fig. 3b). The highest energy conditions occurred during tides 7 (March 22), 25 (March 30) and 26 (March 21), when the offshore significant wave height $H_{\mathrm{s}}$ reached just over $4 \mathrm{~m}$ (see also Fig. 3). The offshore significant wave period was $4-12 \mathrm{~s}$ and showed an overall increase over the duration of the period. Due to the shelter provided by the subtidal and inter-tidal bar systems, the incident wave conditions at the base of the upper beach had a much lower energy, and the inshore significant wave height recorded $20 \mathrm{~m}$ seaward of the swash rig (at $x=80 \mathrm{~m}$; refer Fig. 7) was about $1 \mathrm{~m}$.

The contour plot in Fig. 12c shows the change in beach morphology relative to the average morphology over the field experiment. Compared to the average beach profile, the region affected by high-tide swash processes (i.e. located between the high-tide run-up limit and the hightide water level) has a relative surplus of sediment during tides 1-6 (March 19-21) and tides 21-33 (March 28 to April 4) and a relative lack of sediment in the intermediate period. The reverse is true for the region seaward of the high-tide level, suggesting that the profile response was tide swash zone. White and black in the contour plot represent a difference in bed level of +0.1 and $-0.3 \mathrm{~m}$, respectively, and heavy dashed lines are the approximate run-up limit and the position of the high-tide water level. The offshore wave conditions were measured in $20 \mathrm{~m}$ water depth offshore from Truc Vert and the inshore wave heights were recorded at the base of the high-tide beach at $x=80 \mathrm{~m}$. The numbers 1-33 at the top of the figure represent the monitored tidal cycles

mainly the result of cross-shore sediment exchange (cf. Masselink et al. 2009, pp 21-23).

A more detailed account of the morphological development in the high-tide swash zone reveals four distinct phases: modest onshore sediment transport $\left(0-1 \mathrm{~m}^{3} / \mathrm{m}\right.$ of beach width per tide, henceforth referred to as square metres per tide) and berm building during tides 1-5 (March 19-21), significant offshore sediment transport up to $4 \mathrm{~m}^{2}$ per tide and beach erosion during tides 6-12 (March 21-24), modest onshore sediment transport (about $0.5 \mathrm{~m}^{2}$ per tide) during tides 13-23 (March 25-29) and minimal net sediment transport and beach stability during tides 24-32 (March 30 to April 3, Masselink et al. 2009). The berm building phase was examined by Russell et al. (2009) and is clearly related to the relatively moderate wave conditions that prevailed at the time, possibly enhanced by the increasing tide range, which is known to promote berm building (e.g. Austin and Masselink 2006; Weir et al. 2006). Persistently high, and similar, offshore wave conditions occurred during tides 6-23, and wave variability cannot be invoked to explain the erosion-accretion-stability sequence during this period. The initial erosion can be linked to the onset of the high-energy 
wave conditions and the removal of a small berm on the upper beach, whereas the stability at the end of the monitoring period can be attributed to the establishment of equilibrium.

The explanation for the switch from erosion to accretion during tide 13 (March 25) is less straightforward. Accretion commenced when the tide range began to decrease and the swash processes increasingly encountered a more gentle beach gradient due to the concave-upward shape of the beach profile (note that the changing beach gradient in Fig. 12e does not represent the morphological response but reflects the location of the high-tide swash zone). The highenergy swash conditions acting on the steep upper part of the beach $(\tan \beta=0.07-0.09)$ during tides 6-12 (March 2124) were erosive, but similar swash action on the gentler sloping lower part of the beach $(\tan \beta=0.05-0.08)$ during tides 13-23 (March 25-29) was accretionary, pointing to a beach gradient control of swash zone sediment transport.

A further insight into the relation between beach face morphology and swash zone processes is obtained by focusing on tides 4 (March 20) and 11 (March 24), representing an accretionary and an erosive tide, respectively. Wave conditions during tide 4 (March 20) were some of the lowest energy waves encountered during the field period and net onshore sediment transport prevailed across the 10-12-mwide swash zone (Fig. 13-left panels). During tide 4 (March 20), the lower swash zone eroded by about $0.05 \mathrm{~m}$, while the upper swash zone accreted by some $0.08 \mathrm{~m}$. Overall, the high-tide swash zone gained $1 \mathrm{~m}^{2}$ of sediment (not shown), the upper beach steepened and a small berm was constructed. The swash zone during tide 11 was characterised by a width
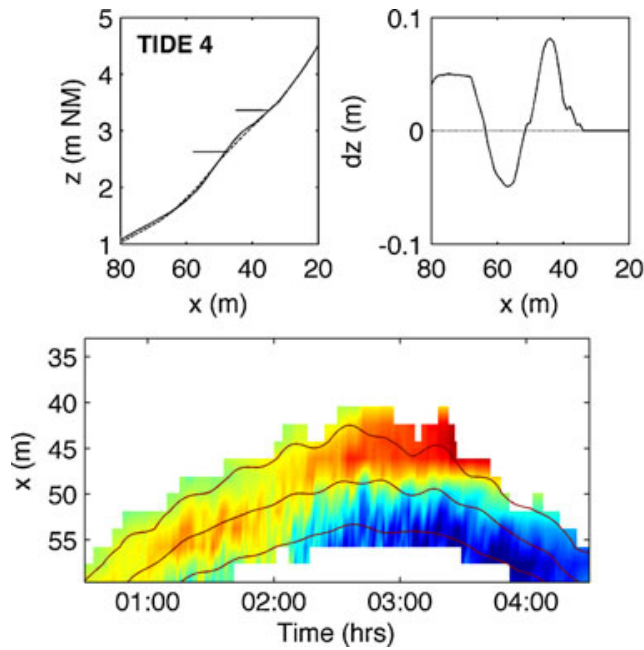

Fig. 13 Morphological change on the upper beach during the accretionary tide 4 (March 20, left panels) and the erosive tide 11 (March 24, right panels). The upper panels show the morphology $z$ before (dashed line) and after (solid line) and the morphological change $\mathrm{d} z$ for tides 4 and 11 ( $x=$ cross-shore distance from the base of the dunes). The small horizontal lines represent the high-tide run-up limit (upper line) and the high-tide water level (lower line). The lower of $25 \mathrm{~m}$ (Fig. 13 - right panels). The upper beach eroded by up to $0.05 \mathrm{~m}$ and $0.5 \mathrm{~m}^{2}$ of sediment was lost from the hightide swash zone. Although net erosion occurred over the high-tide swash zone, a small amount of accretion occurred around the run-up limit.

The differing upper beach responses during tide 4 (March 20) and tide 11 (March 24) occurred due to distinct differences in the inner surf zone and swash hydrodynamics (Fig. 14). The inshore wave spectrum for tide 4 (March 20) is dominated by an 11-s incident wave peak and a small infragravity peak at $102 \mathrm{~s}$, while the tide 11 (March 24) wave spectrum is characterised by two infragravity energy peaks at 27 and $128 \mathrm{~s}$. Tide 4 (March 20) had significantly less energy (offshore $H_{\mathrm{s}}=1.0 \mathrm{~m}$; inshore $H_{\mathrm{mo}}=0.5 \mathrm{~m}$ ) than tide 11 (March 24, offshore $H_{\mathrm{s}}=2.1 \mathrm{~m}$; inshore $H_{\mathrm{s}}=0.8 \mathrm{~m}$ ), and the different energy levels and frequency partitioning are also apparent in the swash hydrodynamics. The time series of swash depth, velocity and runup indicate a dominant swash period of 10-15 s during tide 4 (March 20) and 20-30 s during tide 11 (March 24). Swash events during tide 4 (March 20) were generally free swashes (simple up-down motion), while interacting swash events were more common during tide 11 (March 24). Swash flows during tide 11 (March 24) generally had higher energy, especially during the backwash. The mean flow velocity over the 150-s time series for tide 4 (March 20) was $0.04 \mathrm{~ms}^{-1}$, while for tide 11 (March 24) it was $-0.25 \mathrm{~ms}^{-1}$. This is in accordance with the observed net sediment transport direction over the tidal cycle and the resulting beach response (i.e. accretion during tide 4 and erosion during tide 11).
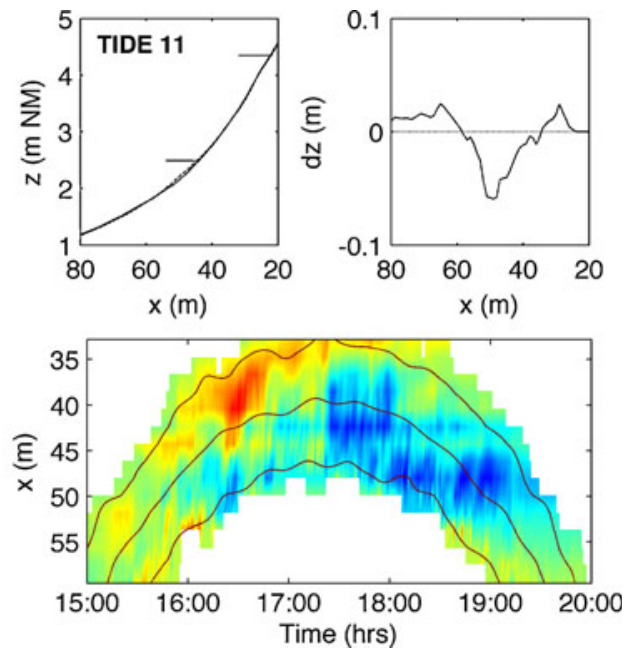

panels show the morphological change relative to the start of the tide recorded with the bed-level sensors. The morphological change was considered at 1-min time intervals and the three lines in each of the panels represent (from top to bottom) the $10 \%, 50 \%$ and $90 \%$ swash inundation percentages smoothed over $15-\mathrm{min}$ time intervals. The colour axis runs from $0.08 \mathrm{~m}$ (dark red) to -0.08 (dark blue) 
Tide 4
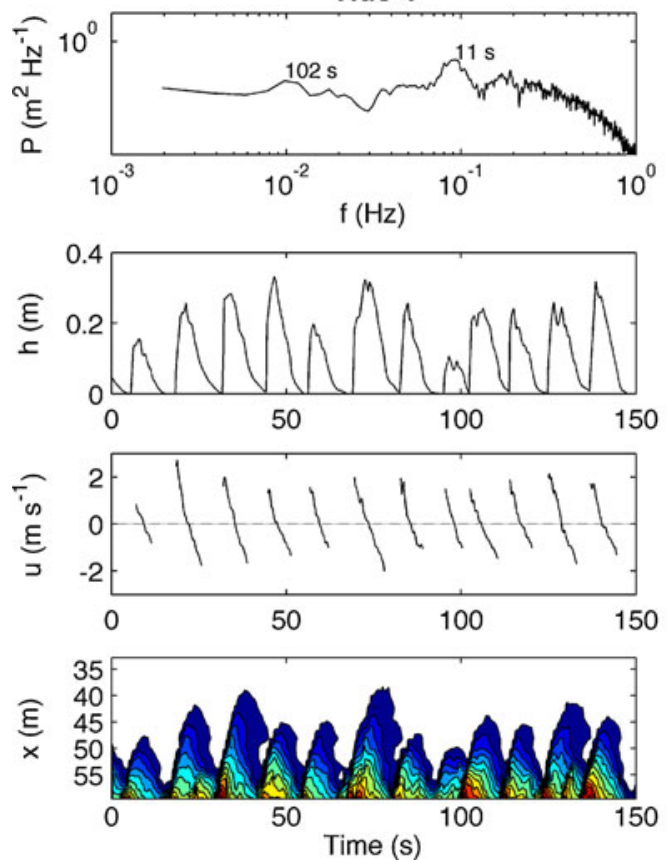

Fig. 14 Swash hydrodynamic conditions during the accretionary tide 4 (March 20, left panels) and the erosive tide 11 (March 24, right panels). The top panels show wave spectra computed from the data collected by the inshore wave sensor (at $x=80 \mathrm{~m}$, Fig. 7). The wave spectra were computed for a 34-min section of data collected during the rising tide with an average water depth of $0.8 \mathrm{~m}$ so the spectra are directly comparable. The spectra were computed using four nonoverlapping, Hamming-tapered segments and have $8^{\circ}$ of freedom. The frequency resolution of the spectra is $0.002 \mathrm{~Hz}$. The other panels

In addition to the above insights that identified the role of swash zone processes in forcing the observed beach face accretion and erosion trends during the experiment, the deployment of the extensive array of BLS ultrasonic bedlevel sensors (refer to Section 3.2.1) also enabled net crossshore sediment fluxes associated with many thousands of individual swashes to be quantified (Blenkinsopp et al. 2009, 2011). It was revealed that, regardless of the direction of net morphological change on a tidal time scale, measured swash-by-swash fluxes are essentially normally distributed, with nearly equal numbers of onshore and offshore events. The majority of swash events caused net cross-shore sediment fluxes smaller than $\pm 50 \mathrm{~kg} / \mathrm{m}$ and the mean sediment flux per swash $O( \pm 1 \mathrm{~kg} / \mathrm{m})$ leading to limited overall morphological change. However, much larger events which deposited or removed several hundred kilograms of sand per metre width of beach were observed at irregular intervals throughout the course of the tide.

Measurements recorded in the surf zone $90 \mathrm{~m}$ from the foot of the dune (referred as LEGI in Fig. 5) are used to discuss the wave-induced change in sand bed. Changes in bed elevation for two series of tides are presented in Fig. 15. For the first series in March, the frame supporting
Tide 11
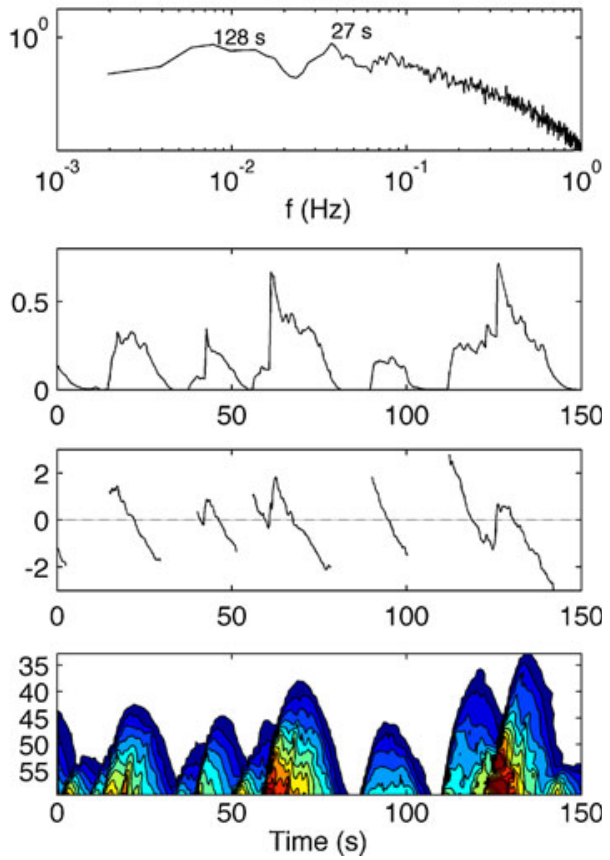

show, from top to bottom, time series of swash depth $h$ measured using bed-level sensor deployed at $x=52 \mathrm{~m}$, Fig. 7; time series of crossshore current velocity $u$ measured at $x=52 \mathrm{~m}$ (Fig. 7) and contour plot showing the time-space change in the swash motion expressed by the swash depth measured with the bed-level sensors. The colour axis runs from 0 (dark red) to $0.8 \mathrm{~m}$ (dark blue). The 150-s time series represents high-tide conditions for tide 4 and rising tide conditions for tide 11

the instruments was located in the surf zone at high tide as shown by the values of $h$ and $H_{\mathrm{s}}$ in Fig. 15a. For the second series in April, the frame was located in the shoaling zone for most tides with significant wave heights barely exceeding $0.6 \mathrm{~m}$ (Fig. 15c). Due to local scour around the beam supporting the optical sensors, the corresponding measured erosion is about $5 \mathrm{~cm}$ greater than that deduced from the acoustic system. General trends are nevertheless very similar for both instruments. For calm wave conditions, the average bed level does not change much during the tides (April 5 and 6 in Fig. 15d). Bed-level fluctuations probably correspond to migrating sand ripples approximately $10 \mathrm{~cm}$ high. For higher-energy wave conditions (Fig. 15b), smaller ripples (about $5 \mathrm{~cm}$ high) are observed, but the main feature in bed-level variation is strong erosion of approximately $20 \mathrm{~cm}$ at the beginning of each tide and accretion towards the end. The net variation is a slight accretion of about $5 \mathrm{~cm}$ per tide on March 24 and 25 and a net erosion of 5 to $15 \mathrm{~cm}$ per tide afterwards. This is in agreement with the change in bed level $10 \mathrm{~m}$ onshore (at $x=80 \mathrm{~m}$ ) shown in Fig. 12. These findings therefore confirm the overall oscillation of the upper beach profile during these high-energy wave conditions (with significant offshore wave 
Fig. $15 a, c$ Water depth (thin line) and significant wave height (thick line); $b, d$ bed elevation measured with optical sensors (thin line) and ADVP (dots) and at low tide (horizontal thick lines). The two series of tides correspond to relatively highenergy ( $a$ and $b$ in March) and calm ( $c$ and $d$ in April) wave conditions
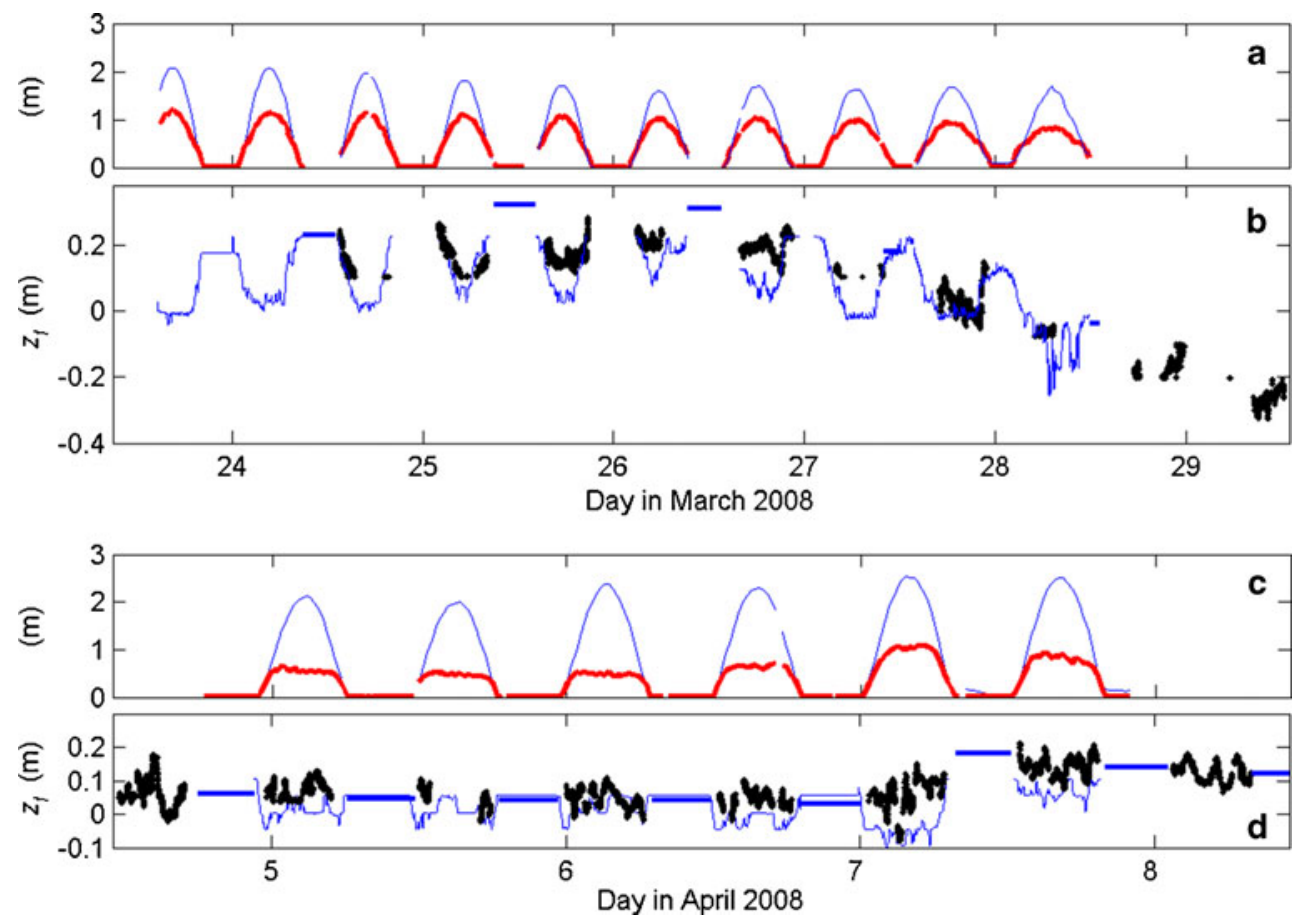

heights $H_{\mathrm{s}}$ of 2 to $3 \mathrm{~m}$ ): The beach slope first becomes flatter until March 26 and then steepens afterwards. Moreover, the initial erosion and final accretion within the tidal cycle also probably indicate an oscillation of the upper beach profile during each tide. The swash-induced beach response shown for March 24 in Fig. 13 is also asymmetric with slight accretion at the beginning of the tide and stronger erosion after high tide. Associated with the measurements at $x=90 \mathrm{~m}$ in Fig. 15b, this would suggest that the upper beach profile steepens during the rising tide and becomes flatter during the ebb tide.

\subsubsection{Preliminary observations of watertable dynamics along a cross-shore transect}

Figure 16 presents an example of the comparison of pressure heads between two overlying sensors (Fig. 5 referred as LSEET). The upper sensor, referred to as $\mathrm{H} 0$, is located just below the sand surface while the lower one, called $\mathrm{H} 1$, is $0.9 \mathrm{~m}$ below the sand surface. In this example, the significant height of incoming swell waves was $4 \mathrm{~m}$ and the tidal range was $3.75 \mathrm{~m}$. Measurements start nearly at low tide, and the duration is around $3 \mathrm{~h}$. Vertical axis is pressure head calculated from pressure data from which water surface elevation can be deduced assuming a hydrostatic pressure distribution and accounting for the vertical position of the sensor. At low tide, only the lower sensor is saturated by water, clearly indicating that the watertable (or phreatic surface) is located between the sensors. Using the estimation of Turner and Nielsen (1997), the capillary fringe height is expected to be around $20 \mathrm{~cm}$, i.e. the upper sensor is above the fully saturated region. The upper sensor is at atmospheric pressure and the constant water level shown until $t=44,800 \mathrm{~s}$ thus corresponds to the position of the $\mathrm{H} 0$ sensor. As the tide starts to rise, i.e. $42,500<t<45,000 \mathrm{~s}$, the lower sensor measures the slow and regular rise in the water table in the sand. Then, at $t=$ $44,800 \mathrm{~s}$, two simultaneous peaks are observed on both sensors, each measuring a rise of around $0.1 \mathrm{~m}$. This feature repeats itself several times until the watertable reaches the upper sensor around $t=46,000 \mathrm{~s}$. The return period is of the order of $150 \mathrm{~s}$, i.e. in the infragravity spectrum. One interesting feature is that the lower sensor peak does not reach the same water elevation that the upper one. As the upper sensor is above the phreatic surface, the dynamics is different from the one presented by Turner and Nielsen

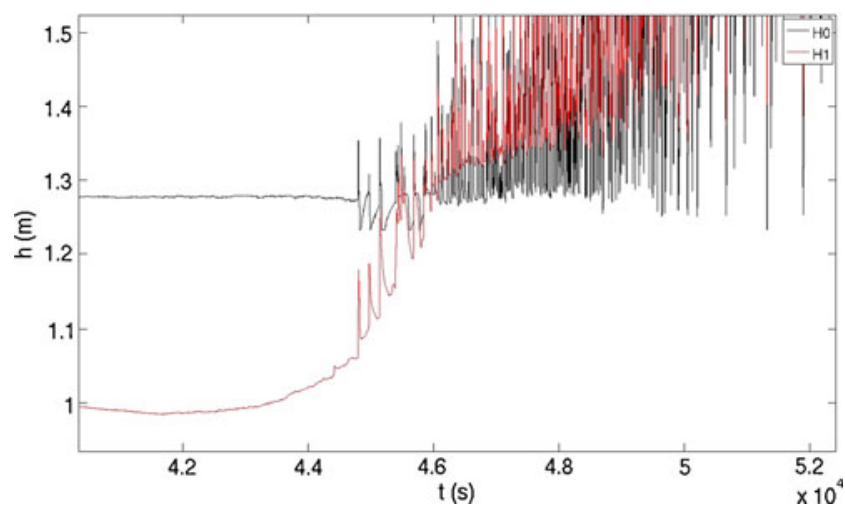

Fig. 16 Water level measured from two overlying buried pressure sensors during the first hours of the incoming tide. $\mathrm{H} 0$ and $\mathrm{H} 1$ are the upper (black line) and lower (red line) sensors, respectively 
(1997) in which pressure oscillations are due to the fluctuations of the atmospheric pressure surface elevation than in the zone of tension saturation, in response to incoming waves. Here, the simultaneous responses of each sensor are not simply due to the rise of the phreatic surface, which would be revealed by the same water levels for both sensors. It appears that the water layer brought by the swash event rapidly infiltrates and is felt by the upper sensor which is located just below the sand surface. At the same time, a groundwater pressure wave hits the lower sensor. This increase of pressure is necessarily associated with a rise of the phreatic surface, but which is not sufficient for the top of the capillary fringe to reach the upper sensor. It is also worth noting that a decrease in pressure is measured on the upper sensor after each swash event, which corresponds to a period of negative relative pressure as the water layer sinks into the sand. By contrast, the lower sensor indicates an increase in water height between the swash peaks confirming that pressure measurements are not simply linked together by the phreatic surface fluctuations. This trend is repeated for the first three swash events of the incoming tide. Between $t=45,500 \mathrm{~s}$ and $t=46,000 \mathrm{~s}$, a transition period is observed during which the upper sensor progressively enters the capillary fringe, allowing for the surface of atmospheric pressure to rise up to the free surface during the swash overtopping. From $t=46,000 \mathrm{~s}$, the sensor is directly exposed to the swash beat and the frequency of recorded swash waves greatly increases. An extensive analysis of data is under way to explore to what extent the groundwater dynamics is dependent upon the forcing conditions.

\subsection{Large-scale morphology evolution during the field experiment}

In the precedent section, detailed observations of smallscale bed-level change have been reported; here we present an overview of large-scale observations. Two weeks before the beginning of the field experiment, TVB had a well-developed crescentic subtidal bar system (Fig. 17a), typical of previous observations (Lafon et al. 2004; Castelle et al. 2007) with a mean wavelength of about $620 \mathrm{~m}$ and a symmetrical shape. A transverse bar and rip system is also observed in the inter-tidal domain. No berm was present, but a well-developed embryo dune area was observed.

The outer bar was situated about $400 \mathrm{~m}$ from the midtide shoreline. At the beginning of the field experiment (March 3), the outer bar was unchanged but the inner bar was relatively $2 \mathrm{D}$ with an alongshore-averaged cross-shore position of $100 \mathrm{~m}$ from the shoreline. During the $8.1-\mathrm{m} H_{\mathrm{s}}$ storm (on March 11), video images showed the straightening of the outer bar and its migration $100 \mathrm{~m}$ offshore after about 1 day (Almar et al. 2009, 2010). The outer bar straightening resulted, in part, from the break-off of the former outer-bar horns from the outer bar. These former horns migrated onshore and welded to the inner bar creating a large input of sand from offshore, despite the severe wave conditions (see Almar et al. 2010 for a complete analysis of the process). In contrast to the outer bar, inner bar alongshore non-uniformity increased during the storm, but its alongshore-averaged position remained largely unaltered. The increase in the alongshore non-uniformity of the inner bar was ascribed to the welding of the former outer-bar horn. Video coverage of a 1,200-m alongshore distance over the inner bar enabled this process to be observed continuously, but only over a single outer-bar horn. Bathymetric surveys performed along a 2,400-m alongshore distance at the end of the field experiment (Fig. 17b) suggest that similar processes might also take place at the other former outer-bar horn positions.

Analysis of topographic surveys showed that peak erosion of the upper part of the beach lagged the storm peak by 1 day (Capo et al. 2009). It is believed that this is linked to the weakened protection of the outer bar associated with its offshore migration. The data have also revealed that the erosion was not uniform in the cross-shore and alongshore directions (Capo et al. 2009). This is consistent with visual observations at the instrument rigs. Several rigs were severely damaged due to the considerable seabed erosion whereas, at the same time, the seabed at other rigs did not erode at all. Nevertheless, overall this induced a straightening of the contours on the beach face (Rejas et al. 2009). The combination of high waves and spring tide (tidal range close to $4.5 \mathrm{~m}$ ) also eroded the base of the embryo dune at several locations (about $1 \mathrm{~m}$, Capo et al. 2009).

Another storm occurred 5 days after the $8.1-\mathrm{m} H_{\mathrm{s}}$ storm, which was less intense and coincided with neap tidal conditions. This storm on March 15 did not affect the outer bar but the inner bar increased its alongshore nonuniformity (Almar et al. 2009, 2010). The former outerbar horn was still observed to be welded to the inner bar. Similarly, an increase in undulating patterns was observed on the lower beach face (Rejas et al. 2009).

After this second storm, TVB experienced a long period (14 days) of high-energy swell conditions $\left(H_{\mathrm{mo}}\right.$ ranging between 2 and $4 \mathrm{~m}$ ). During this period, the outer bar developed crescentic patterns (Fig. 6b) that migrated about $200 \mathrm{~m}$ southward, with negligible overall crossshore migration (Almar et al. 2010). The undulating patterns on the lower beach face during this period increased drastically (Rejas et al. 2009) and migrated southward by about $100 \mathrm{~m}$.

The observed morphological changes were reflected in the sand grain size maps that were collected (Gallagher et al., submitted for publication). Five grain size surveys were 

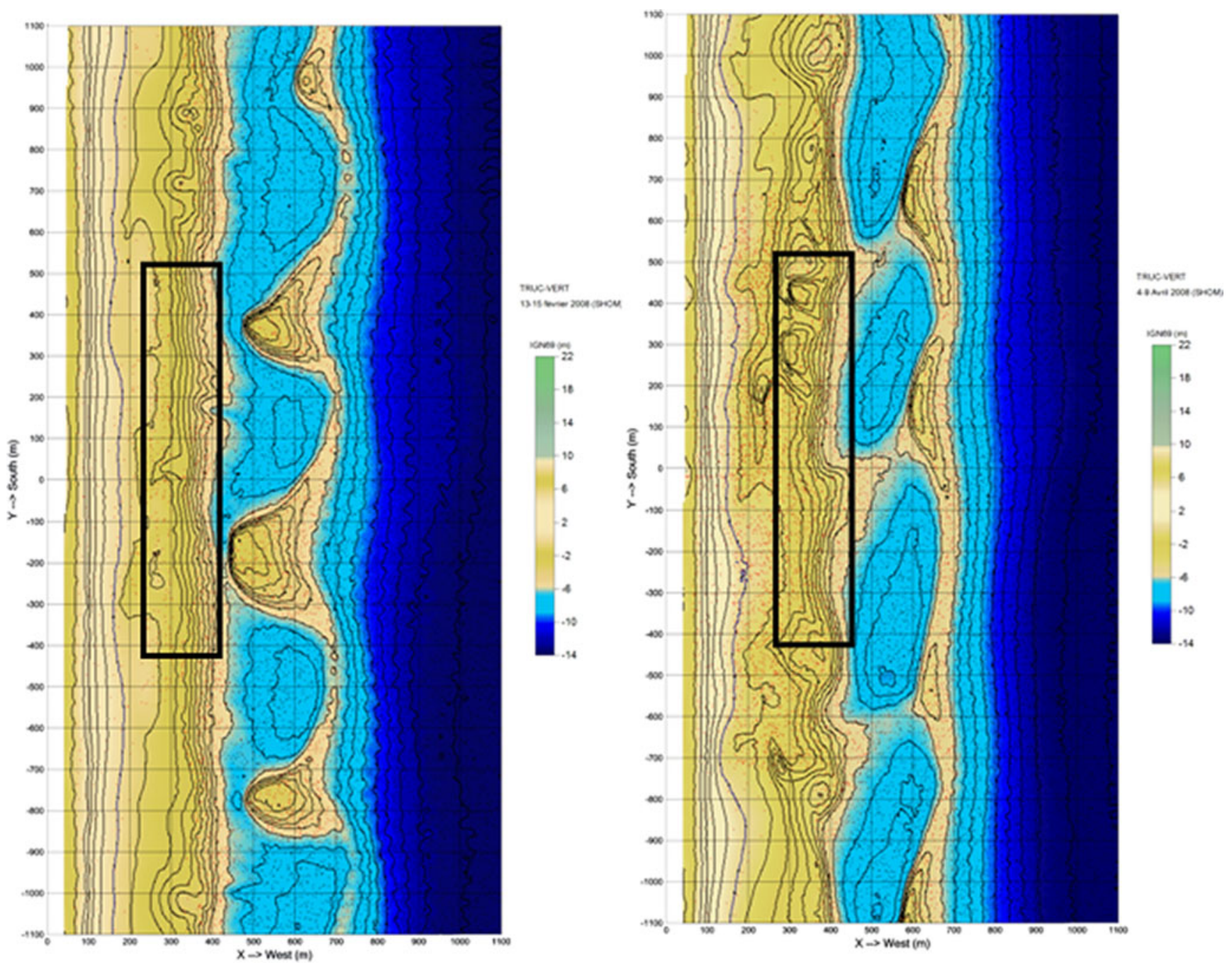

Fig. 17 Bathymetry surveys: a at the beginning of the field experiment, $\mathbf{b}$ at the end of the field experiment. The black rectangle represents the area of inter-tidal deployment

completed over the inner-bar region (March 14, 17 and April), and grain size was found to be coarser in the deep rip channels, finer on the migrating shoals and finest higher on the dry beach. In addition, this spatial pattern of grain size variability changed with the bathymetry as storm waves forced the inner bar to change shape and the rip channel-shoal system migrated.

\subsection{Intermediate-scale hydrodynamic processes}

In the two previous sections, the focus was essentially on morphologic changes at different spatial and temporal scales, including single swash/wave events to several swash/wave events (1D cross-shore berm dynamic) and finally the large-scale evolution of the beach. In this section, we will present preliminary results on the impact of this evolving surf zone bathymetry on nearshore currents that depend strongly on this bathymetry.

\subsubsection{Mean inter-tidal surf zone circulation patterns}

There was significant bathymetric variability within the inter-tidal surf zone (Fig. 5) that induced unique surf zone circulations that were strongly affected by the tides. As it is difficult to describe these circulation patterns with fixed Eulerian instruments, GPS-equipped drifters were released in the inter-tidal surf zone.

On April 1, the wave conditions were near normally incident $\left(H_{\mathrm{s}}=1.8 \mathrm{~m}, T_{\mathrm{mo}}=11 \mathrm{~s}\right.$ and $\theta_{\mathrm{mo}}=15^{\circ}$ in $20 \mathrm{~m}$ water depth), the drifters moved in a counter-clock wise pattern (upper left panel of Fig. 18) on the southern side of the rip channel at $y=400-550 \mathrm{~m}$. The closed surf zone circulation pattern was coupled with the inter-tidal morphology and contained within the active breaking region and resulted in minimal inter-tidal surf-zone drifter exits (upper left panel of Fig. 18; consistent with MacMahan et al. 2010a). The subtle (average rip channel slope 1:65) alongshore bathy- 

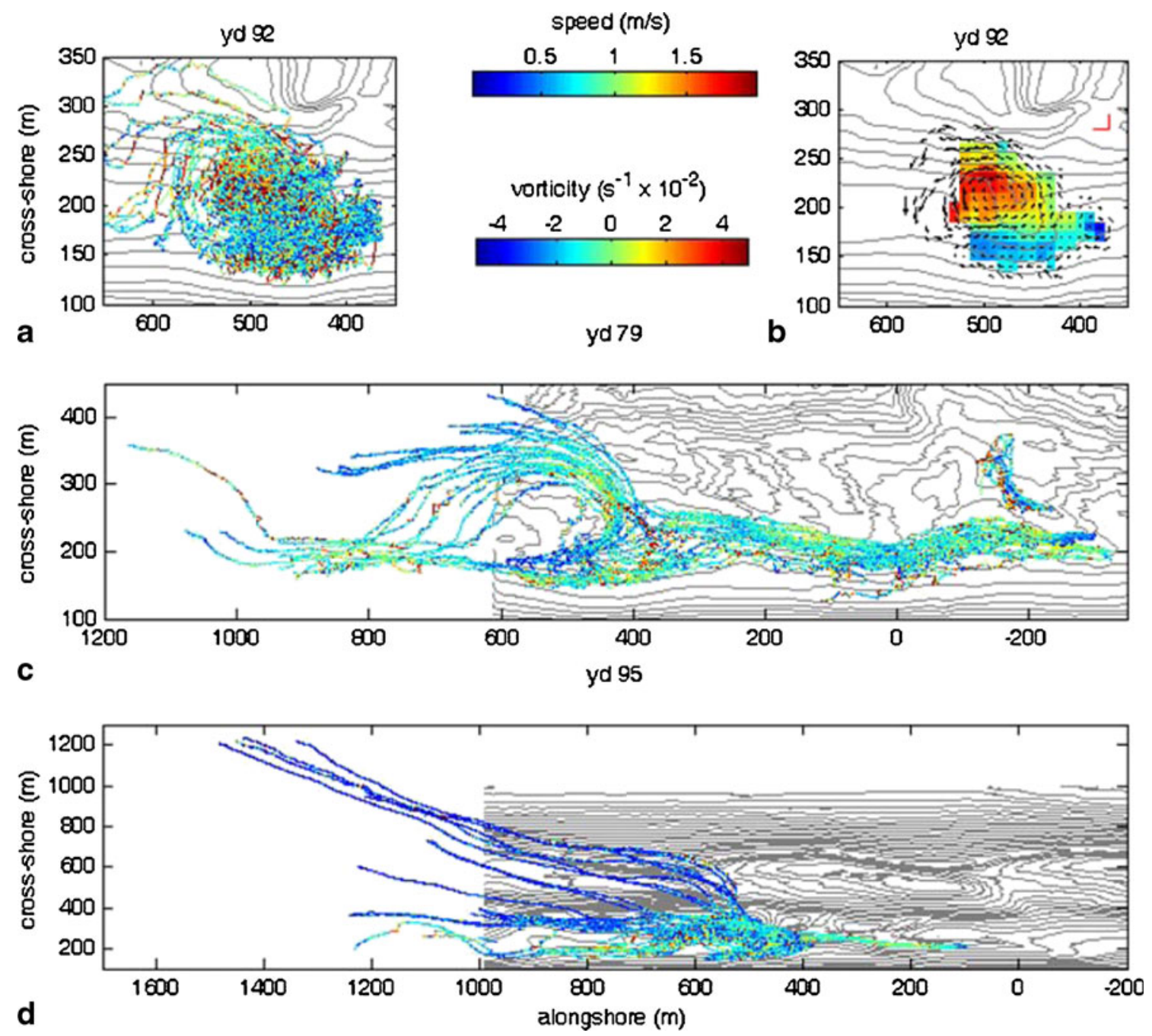

Fig. 18 Drifter position and speed (the colour of the line represents speed) tracks for drifter deployments on March 19 (c), April, 1 (a) and April 4 (d). The colour bars at the top represent drifter speed and vorticity. Drifter velocity data are sorted into $10 \times 10 \mathrm{~m}$ bins and averaged over the deployment duration $(\sim 3 \mathrm{~h})$ for April 1. Vectors (d) are shown only for bins with more than five independent observations
(MacMahan et al. 2010a). The red arrows in the upper right-hand corner provide vector scales. Colour represents vorticity estimated from velocity observations. Bathymetric contours are plotted in the background in grey. Note that there are differences in alongshore scales

tide cutoff of the rip current development. As a result, rip currents at Truc Vert develop around mid-tides (Castelle et al. 2007; Austin et al. 2009; Bruneau et al. 2009) and are non-existent at low tides.

Also observed on April 1 near the shoreline was the development of two smaller clockwise circulations, highlighting the complexity of the circulation patterns associated with the inter-tidal morphology (upper right panel of Fig. 18). This is the first field evidence of these smaller shoreline circulations patterns, which were first found in the laboratory by Haller et al. (2002). It is suggested that a reversal of alongshore pressure and wave forcing gradients develop near the shoreline that induce the clockwise circulation patterns. The shoreline circulation patterns were not observed at Sand City, Monterey (MacMahan et al. 2010a). This difference is 
believed to be related to the steeper sloping subaerial beach face at Sand City relative to the milder sloping beach face at Truc Vert.

On March $19\left(H_{\mathrm{s}}=1.3 \mathrm{~m}, T_{\mathrm{mo}}=12.3 \mathrm{~s}\right.$ and $\left.\theta_{\mathrm{mo}}=70^{\circ}\right)$, an alongshore current developed owing to the larger angle of wave incidence related to the storm. To map the alongshore current, drifters were released farther up the beach to the north. The drifters migrated towards the south at $\sim 1 \mathrm{~m} / \mathrm{s}$ until they encountered the rip channel around $y=450 \mathrm{~m}$, which was oriented obliquely to the shoreline and normal to the angle of wave incidence, causing the drifters to make an abrupt directional change moving seaward through the channel (middle panel of Fig. 18). This was a surprising deviation from their alongshore migration pathway which highlights the influence of local morphologically induced flow behaviour. No closed surf zone circulation pattern was observed, as found on April 1. Instead, a number of drifters exit the inter-tidal surf zone that returned onshore farther down the beach at the inter-tidal shoals.

Since a minimal number of drifters exited the inter-tidal surf zone during conditions deemed operationally safe for drifter deployment, little information was obtained about the circulation patterns of the outer crescentic bar. Those that did exit the inter-tidal surf zone were quickly captured and returned to the beach owing to the hazardous breaking wave conditions for personal watercraft operations and limited line of sight. On April 4, the smaller wave conditions $\left(H_{\mathrm{s}}=0.9 \mathrm{~m}\right.$, $T_{\mathrm{mo}}=11.4 \mathrm{~s}, \theta_{\mathrm{mo}}=25^{\circ}$ ) resulted in drifters exiting the intertidal system and floating seaward toward the outer crescentic bar and beyond (lower panel of Fig. 18). The reduced wave height resulted in minimal wave breaking at the outer bar and reduction in associated offshore circulation patterns. There is a small deflection in the drifter pathways near the outer crescentic bar suggesting that the bar morphology has an influence. The drifters moved $\sim 1 \mathrm{~km}$ offshore with a constant cross-shore velocity of $10 \mathrm{~cm} / \mathrm{s}$.

In summary, the observations from the GPS-equipped drifters provided a synoptic view of the inter-tidal surf zone circulation patterns. It was found the inter-tidal morphology had a significant role on the observed circulations and drifter behaviours. The drifter results highlighted new observations of rip current circulations associated with subtle bathymetric variations, flow reversals in the presence of strong alongshore currents and shoreline circulation patterns, as well as rip current flow patterns similar to other rip-channelled beaches.

\subsubsection{Inter-tidal infragravity $(0.004 \leq f \leq 0.04 \mathrm{~Hz})$ and very low-frequency $(f \leq 0.004 \mathrm{~Hz})$ motions}

IG waves are generated by wave groups made up of directionally spread incident waves. IG waves can be separated into leaky waves and refractively trapped edge waves (Herbers et al. 1995). VLF motions consist of current shear instabilities (Oltman-Shay et al. 1989; Dodd et al. 2000; Noyes et al. 2004; Haller and Dalrymple 2001) and wave-group-forced vortical motions (Ryrie 1983; Reniers et al. 2004, 2007; Long and Özkan-Haller 2009; MacMahan et al. 2010b).

Both IG and VLFs motions can be coupled to the local bathymetry. This was shown numerically by Bryan and Bowen (1996) and Reniers et al. (2006) for bathymetrically coupled edge waves. MacMahan et al. (2004) used a frequency-alongshore wavenumber $\left(f-k_{y}\right)$ analysis to show the presence of bathymetrically coupled VLFs, $<0.004 \mathrm{~Hz}$ on a rip-channelled beach. To date, IG and VLF motions on beaches with pronounced morphologic variability have only been studied in the field at Sand City, Monterey Bay, CA, USA. The field experiment at Truc Vert provided a new field site to study these motions on a different beach with significant inter-tidal morphologic variations. Furthermore, the behaviour, in particular the alongshore scales of these motions on under significant storm conditions, has not been observed until now.

To examine the potential coupling of IG and VLF motions with the underlying bathymetry, we compare the alongshore length scales in bathymetry and fluid motions. To resolve the frequency-alongshore wavenumber $\left(f-k_{y}\right)$ spectrum of the IG and VLF motions a coherent, synchronous, alongshorelagged array (referred as puv 1 to puv 7 in Fig. 5) is required. Energy located at $k_{y}=0$ corresponds to normally incident motions ( $u$ velocities only), whereas energy at non-zero $k_{y}$ values corresponds to alongshore propagating motions (presence of $v$-velocity. $f-k_{y}$ spectra were calculated using the iterative maximum likelihood estimator (IMLE) (Pawka 1983) evaluated by Oltman-Shay and Guza (1987) for detection of edge waves and later by Oltman-Shay et al. (1989) for the detection of alongshore current shear instabilities. Each cross-spectral value was normalized so that the diagonals of the cross-spectral matrix are unity. Spectral estimates with $30^{\circ}$ of freedom (frequency resolution of $0.0006 \mathrm{~Hz}$ ) were generated from de-meaned, quadratically detrended $4.8 \mathrm{~h}$ records around high and low tide, when the conditions are stationary validated by constant mean velocities. A basic assumption of the IMLE is spatial homogeneity, which is not necessarily expected over bathymetry with quasiperiodic rip channels. Numerical simulations based on field observations found that the IMLE is applicable for a ripchannelled beach (MacMahan et al. 2004; Reniers et al. 2007). The $f-k_{y}$ spectra for cross- and alongshore velocities and pressure were computed for the 10-year storm on March 11 and the 5-m $H_{\mathrm{mo}}$ storm on March 16 at high tide. For the March 11 storm, puv 6 and 7 were not operational, which reduced the overall array length and the corresponding $k_{y}$ resolution of the IG and VLF motions. The 10-year storm had an oblique angle of incidence generating an alongshore 
current of $1.1 \mathrm{~m} / \mathrm{s}$ at high tide in the $3-\mathrm{m}$ water depth. The IG, $0.004-0.04 \mathrm{~Hz}$, rms speed and wave height were $0.66 \mathrm{~m} / \mathrm{s}$ and $1 \mathrm{~m}$. A high-energy linear ridge for positive $k_{y}$ was observed in the cross- and alongshore velocity $f-k_{y}$ spectra associated with alongshore current shear instabilities. The distribution of the alongshore velocity energy density is not symmetric with respect to $k_{y}=0 \mathrm{~m}^{-1}$ and as a result does not match the theoretical constant-slope edge-wave dispersion curves (left middle panel in Fig. 19). This can be attributed to the presence of a strong alongshore current velocity on which the edge waves refract resulting in smaller (larger) $k_{y}$ for edge waves propagating with (against) the alongshore current (Howd et al. 1992). This effect is partly obscured by the earlier mentioned reduced $k_{y}$ resolution of the alongshore array (Fig. 19). A strong frequency nodal structure is observed in the $f-k_{y}$ spectra and in the $k_{y^{-}}$ integrated spectra related to cross-shore standing IG motions.
Interestingly, the lower-frequency IG motions have the highest energy levels. No relationship was found between the IG and VLF motions and inter-tidal morphology during this extreme storm. It is hypothesized that the advection by the strong alongshore current inhibits the coupling of IG and VLF motions with the inter-tidal bathymetric features.

During the $5-\mathrm{m} H_{\mathrm{s}}$ storm, the angle of wave incidence was relatively shore-normal producing minimal alongshore currents. The IG rms speed and wave height were $0.37 \mathrm{~m} / \mathrm{s}$ and $0.5 \mathrm{~m}$. Energy peaks occur in the VLF band around $k_{y}= \pm 0.004 \mathrm{~m}^{-1}$ for the cross-shore velocities and broad energy around $k_{y}=0 \mathrm{~m}^{-1}$ for the alongshore velocities (Fig. 19). The cross-shore velocity energy peaks correspond to the inter-tidal rip channel spacing for that day. The $f-k_{y}$ spectral response is similar to observations by MacMahan et al. (2004) on a rip-channelled beach, suggesting that the rip current flow patterns are oscillating predominantly in the
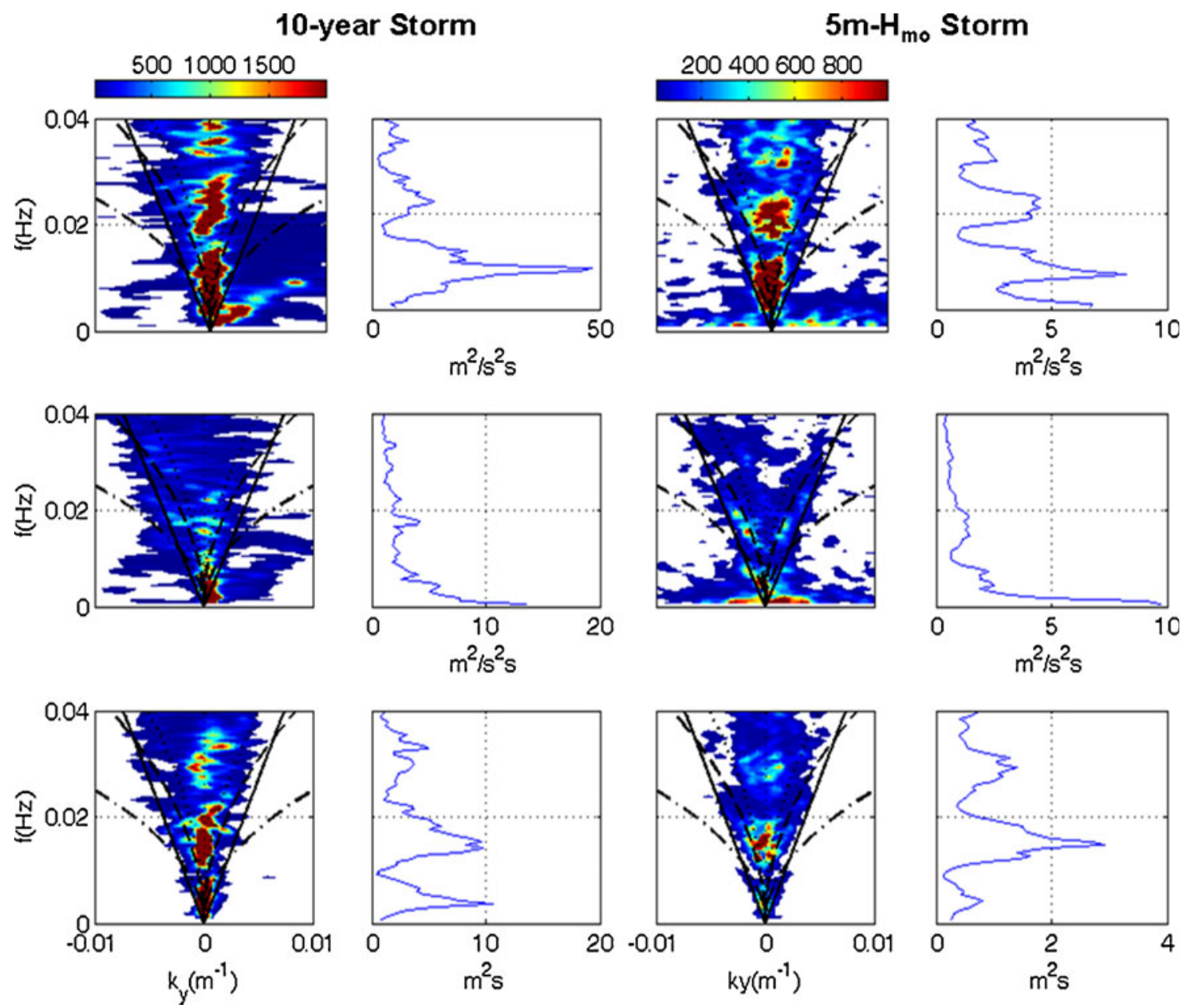

Fig. $19 f-k_{y}$ spectra computed using the IMLE method for crossshore (top row), alongshore (middle row) velocities and pressure (bottom row) for the alongshore array for the 8.1-m $H_{\mathrm{s}}$ storm on March 11 (left columns) and the 5-m $H_{\mathrm{s}}$ storm on March 16 (right columns) at high tide. Corresponding $k_{y}$-integrated spectra plotted to the right of the $f-k_{y}$ spectra. Lines represent mode 0 (dash-dot), 1 (dash-dash) and 2 (dot-dot) edge wave dispersion curves for a planar beach using an inter-tidal beach slope of 1:25 (Eckart 1951). Bold lines are $k_{y}=f(g h)^{-1 / 2}$. Velocity and pressure colour scales are at the top of each $f-k_{y}$ column 
cross-shore and minimally in the alongshore. Within the IG frequency band, high edge-wave energy density for the alongshore velocity is symmetrically distributed around $k_{y}= \pm 0.004 \mathrm{~m}^{-1}$ consistent with the inter-tidal rip-channel spacing and the absence of a strong alongshore current. A similar frequency nodal structure is observed in the $f-k_{y}$ spectra and in the $k_{y}$-integrated spectra that have higher IG energy levels occurring at lower frequencies, but with reduced energy compared to the 10-year storm.

Persistent bathymetrically coupled IG and VLF motions sustain morphological features (Reniers et al. 2004). The present results suggest that in the case of a strong alongshore current, this coupling is absent, as observed during the $8.1-\mathrm{m} H_{\mathrm{s}}$ storm, which could have important consequences for the ability of the inter-tidal beach to reset the morphological length scales.

\section{Summary}

The Truc Vert'08 field experiment has provided new observations that incorporate extreme storm waves (significant wave height up to $8.1 \mathrm{~m}$ in $20 \mathrm{~m}$ water depth), macro-tidal conditions and complex 3D morphology. Results indicate that our knowledge of the hydrosedimentary processes occurring during calm conditions cannot be simply extrapolated to extreme conditions. For example, during the $8.1 H_{\mathrm{s}}$ storm, large inputs of sand from offshore are observed, as a resulting of the former outer-bar horns breaking off from the outer bar (Fig. 17). Observations also indicate that the peak of erosion of the upper part of the beach lagged the peak of the storm. Small-scale, high-frequency observations also indicate that wave variability cannot be invoked to explain the erosion-accretion-stability sequences observed in the morphological development in the high-tide swash zone (Fig. 12). Data also confirm the shift to lowerfrequency processes of both large-scale hydrodynamic processes such as surf currents (Fig. 19) and hydrosedimentary processes on small scales such as swash processes (Fig. 14) during high-energy events.

Overall oscillations of the upper beach during the highenergy conditions are observed (Figs. 11 and 15). Blenkinsopp et al. (2011) revealed that, regardless of the direction of morphological change on a tidal time scale, measured swashby-swash fluxes are essentially normally distributed, with nearly equal numbers of onshore and offshore events, suggesting an oscillation of the upper beach profile during each tide. Bed-elevation measurements during high-energy forcing indicate that the upper beach profile steepens during the rising tide and becomes flatter during the ebb tide (Figs. 13 and 15). Observed temporal bedform variability in the surf zone also reveals that the seabed fluctuates on two distinct time scales (Figs. 8 and 10) under low- and high- energy conditions. Low-pass instantaneous bed-level estimates are associated with temporal bedform dynamics with amplitudes varying with tide but which can be completely smoothed during extremely high-energy events (Fig. 11), possibly because of strong infragravity motions.

Preliminary results clearly describe the behaviour of complex processes taking place at different space and time scales. Video analysis, including for example run-up dynamics and its interaction with the upper beach face, as well as the impact of underlying morphology are still in progress and preliminary results indicate possible saturation of infragravity motions under very high energetic conditions (Sénéchal et al. 2011). Further analysis at each spatial and temporal scale and their future merging should allow to better assess the relationships between the small-scale, intermediate-scale and the large-scale beach processes. At the same time, numerical modelling works should allow for a more in-depth study of the alongshore and cross-shore non-uniformities to better evaluate the intermediate scale.

Acknowledgements We thank all those who have given financial support for this field experiment, in particular the French DGA. GM, PR and IT gratefully acknowledge funding from the UK Natural Environment Research Council (NERC; NE/F009275/1) and the Australian Research Council (ARC; DP0770118) and the assistance of their excellent field team. JHMM, AJHMR and EG gratefully acknowledge the funding from the USA NSF and the assistance of their team. BGR was funded by the Netherlands Organisation for Scientific Research (NWO) under project 864.04.007. We should like to thank NIWA (Hamilton-New Zealand) for providing support in the installation of the video system. We are most grateful to the lifeguards (CRS/MNS) for providing support during the field experiment. We thank the mayor of the city of Lege-Cap Ferret, $\mathrm{Mr}$ Sammarcelli, and his technical staff for providing logistic support. We also really appreciate the support of the French National Forest Office (ONF). Finally, we would like to point out that the list of authors is representative of most of the institutes involved in the field experiment but does not include everyone who contributed to the success of this field experiment. We are sincerely grateful to all the researchers, engineers, technicians, military personnel and students who made the field experiment possible. We greatly appreciated their invaluable help in making this field experiment a success despite the difficult weather conditions.

\section{References}

Aagaard T, Kroon A, Andersen S, Moller Sorensen R, Quartel S, Vinther N (2005) Intertidal beach change during storm conditions; Egmond, The Netherlands. Mar Geol 218:65-80

Almar R, Castelle B, Ruessink BG, Senechal N, Bonneton P, Marieu V (2009) High-frequency video observation of two nearby double barred beaches under high-energy wave forcing. J Coast Res SI56:1706-1710

Almar R, Castelle B, Ruessink BG, Senechal N, Bonneton P, Marieu V (2010) Two- and three-dimensional double-sandbar system behaviour under intense wave forcing and a meso-macro tidal range. Cont Shelf Res 30(7):781-792 
Arnaud G, Mory M, Abadie S, Cassen M (2009) Use of a resistive rods network to monitor bathymetric evolution in the surf/swash zone. J Coast Res SI56:1781-1785

Austin MJ, Masselink G (2006) Observations of morphological change and sediment transport on a steep gravel beach. Mar Geol 229:59-77

Austin MJ, Scott TM, Brown JW, Brown J, MacMahan J (2009) Macrotidal rip current experiment: circulation and dynamics. J Coast Res SI56:24-28

Berni C, Mignot E, Michallet H, Dalla-Costa C, Grasso F, Lagauzère M (2009) Diversity of bed evolution at wave and tidal scales on Truc-Vert beach. J Coast Res SI56:1726-1730

Blenkinsopp CE, Turner IL, Masselink G, Russell PE (2009) Field measurements of net sediment flux from individual swashes on a sandy beach. In: Proc. Coastal Dynamics 2009, Tokyo, paper no. 27

Blenkinsopp CE, Turner IL, Masselink G, Russell PE (2011) Swash zone sediment fluxes - field observations. Coast Eng 58:28-44

Bowen AJ (1969) The generation of longshore currents on a plane beach. J Mar Res 27:206-215

Brander RW (1999) Field observations on the morphodynamic evolution of low wave energy rip current system. Mar Geol 157:199-217

Brander RW, Short AD (2000) Morphodynamics of a large-scale rip current system at Muriwai Beach, New Zealand. Mar Geol $165: 27-39$

Brown J, MacMahan JH, Reniers A, Thornton E (2009) Surfzone diffusivity on a rip channeled beach. J Geophys Res. doi:10.1029/2008JC005158

Bruneau N, Castelle B, Bonneton P, Pederos R, Almar R, Bonneton N, Bretel P, Parisot JP, Senechal N (2009) Field observations of an evolving rip current on a meso-macrotidal inner bar and rip morphology. Cont Shelf Res 29:1650-1662

Bryan KR, Bowen AJ (1996) Edge wave trapping and amplification on barred beaches. J Geophys Res 101(3):6543-6552

Bryan KR, Bowen AJ (1998) Bar-trapped edge waves and longshore currents. J Geophys Res 103(12):27,867-27,884

Bryan KR, Howd PA, Bowen AJ (1998) Field observations of trapped edge waves. J Geophys Res 103(1):1285-1305

Butel R, Dupuis H, Bonneton P (2002) Spatial variability of wave conditions on the French Aquitanian coast using in-situ data. J Coast Res SI36:96-108

Butt T, Russell P, Turner I (2001) The influence of swash infiltrationexfiltration on beach face sediment transport: onshore or offshore? Coast Eng 42:35-52

Capo S, Parisot JP, Bujan S, Senechal N (2009) Short time morphodynamic response of the Truc Vert Beach to storm conditions. J Coast Res SI56:1741-1745

Castelle B, Bonneton P, Sénéchal N, Dupuis H, Butel R, Michel D (2006) Dynamics of wave-induced currents over an alongshore non-uniform multiple-barred sandy beach on the Aquitanian Coast, France. Cont Shelf Res 26(1):113-131

Castelle B, Bonneton P, Dupuis H, Senechal N (2007) Double bar beach dynamics on the high-energy meso-macrotidal French Aquitanian Coast: a review. Mar Geol 245:141-159

Castelle B, Michallet H, Marieu V, Leckler F, Dubardier B, Lambert A, Berni C, Bonneton P, Barthélemy E, Bouchette F (2010) Laboratory experiment on rip current circulations over a moveable bed: drifter measurements. J Geophys Res 115: C12008. doi:10.1029/2010JC006343

Coco G, Murray AB (2007) Patterns in the sand: from forcing templates to self-organization. Geomorphology 91(3-4):271-290

Dalrymple RA (1978) Rip currents and their causes. In: Proceedings of ICCE, ASCE, Hamburg, pp 1414-1427

Davis RE (1991) Observing the general-circulation with floats. DeepSea Res 38:S531-S571
De Melo Apoluceno D, Howa H, Dupuis H, Oggian G (2002) Morphodynamics of ridge and runnel systems during summer. J Coast Res SI36:222-230

Dehouck A, Martiny N, Froidefond J-M, Sénéchal N, Bujan S (2009) New outcomes from spatial remote sensing during the ECORS experiment: towards validation of ocean color products and largescale bathymetry mapping in a coastal zone. J Coast Res SI56:1756-1760

Dodd N, Iranzo V, Reniers AJHM (2000) Shear instabilities of wavedriven alongshore currents. Rev Geophys 38(4):437

Dronen N, Deigaard R (2007) Quasi-three-dimensional modeling of the morphology of longshore bars. Coast Eng 54:197-215

Eckart C (1951) Surface waves on water of variable depth. Wave Rep. 100, Scripps Institution of Oceanography, University of California, San Diego, La Jolla, CA, 99 pp

Emmanuel I, Parisot JP, Michallet H, Barthélemy E, Sénéchal N (2009) Sediment transport particular events and beach profile response. J Coast Res SI56:1766-1770

Feddersen F, Gallagher E, Guza RT, Elgar S (2003) The drag coefficient, bottom roughness, and wave-breaking in the nearshore. Coast Eng 48:189-195

Gallagher EL, Elgar S, Guza RT (1998) Observations of sand bar evolution on a natural beach. J Geophys Res 103:3203-3215

Gallagher EL, Thornton EB, Stanton TP (2003) Sand bed roughness in the nearshore. J Geophys Res 108(C2):3039. doi:10.1029/ 2001JC001081

Gallagher EL, Elgar S, Guza RT, Thornton EB (2005) Estimating nearshore bedform amplitudes with altimeters. Mar Geol 216:51-57

Gallagher EL, MacMahan JH, Reniers Ad JHM (2011) Grain size variability on a rip-channeled beach. Marine Geol (in press)

Garnier R, Calvete D, Falques A, Caballeria M (2006) Generation and nonlinear evolution of shore oblique/transverse sand bars. J Fluid Mech 567:327-360

Grasmeijer BT, Van Rijn LC (2001) Sand transport in the surf zone of a dissipative beach. Coastal Dynamics, Lund, pp 102-111

Grasso F, Michallet H, Barthelemy E, Certain R (2009) Physical modeling of intermediate cross-shore beach morphology: transients and equilibrium states. J Geophys Res 114:C09001. doi:10.1029/2009JC005308

Grasso F, Michallet H, Barthélémy E (2011) Sediment transport associated with morphological beach changes forced by irregular asymmetric-skewed waves. J Geophys Res 116:C03020. doi:10.1029/2010JC006550

Guillén J, Hoekstra P (1996) The "equilibrium" distribution of grain size fractions and its implication for cross-shore sediment transport: a conceptual model. Mar Geol 135(issues 1-4):15-33

Guillén J, Hoekstra P (1997) Sediment distribution in the Nerashore zone: grain size evolution in response to shoreface nourishment (Island of Terschelling, The Netherlands). Estuar, Coast Shelf Sci 45:639-652

Haller MC, Dalrymple DA (2001) Rip current instabilities. J Fluid Mech 433:161-192

Haller MC, Dalrymple RA, Svendsen IA (2002) Experimental study of nearshore dynamics on a barred beach with rip channels. J Geophys Res 107(14):1-21

Herbers THC, Elgar S, Guza RT, O’Reilly WC (1995) Infragravityfrequency $(0.005-0.05 \mathrm{~Hz})$ motions on the shelf, II, free waves. J Phys Oceanogr 25:1063-1079.

Holman RA, Bowen A (1984) Longshore structure of infragravity wave motions. J Geophys Res 89(C4):6446-6452

Horn DP (2002) Beach ground water dynamics. Geomorphology 48:121-146

Howd PJ, Bowen AJ, Holman RA (1992) Edge waves in the presence of strong longshore currents. J Geophys Res 100:24,863-24,872

Hsu TJ, Elgar S, Guza RT (2006) Wave-induced sediment transport and onshore sandbar migration. Coast Eng 53:817-824 
Hurther D, Lemmin U (2001) A correction method for turbulence measurements with a $3 \mathrm{D}$ acoustic Doppler velocimetry profiler. J Atmos Ocean Technol 18(3):446-458

Johnson D, Pattiaratchi C (2004) Transit rip currents and nearshore circulation on a swell-dominated beach. J Geophys Res 109: C02026. doi:10.1029/2003JCC001798

Kroon A, Masselink G (2002) Morphodynamics of intertidal bar morphology on a macrotidal beach under low-energy wave conditions, North Lincolnshire, England. Mar Geol 190:591-608

Lafon V, De Melo Apoluceno D, Dupuis H, Michel D, Howa H, Froidefond JM (2004) Morphodynamics of nearshore rhythmic sandbars in a mixed-energy environment (SW France): I. Mapping beach changes using visible satellite imagery. Estuar Coast Shelf Sci 61:289-299

Long JW, Özkan-Haller HT (2009) Low-frequency characteristics of wave group-forced vortices. J Geophys Res 144:CO8004. doi:1029/2008JC004894

Lorin J, Viguier J (1987) Hydrosedimentary conditions and present evolution of Aquitaine Coast. Bull Inst Bassin Aquitaine 41:95108

MacMahan JHM, Reniers Ad JHM, Thornton EB, Stanton TP (2004) Surf zone eddies coupled with rip current morphology. J Geophys Res 109:C07004. doi:10.1029/2003JC002083

MacMahan JHM, Thornton EB, Stanton TP, Reniers AJHM (2005) RIPEX-rip currents on a shore-connected shoal beach. Mar Geol 218:113-134

MacMahan JHM, Thornton Ed B, Reniers Ad JHM, Stanton TP, Symonds G (2008) Low-energy rip currents associated with small bathymetric variations. Mar Geol 255(3-4):156-164

MacMahan JHM, Brown J, Brown J, Thornton Ed, Reniers Ad, Stanton T, Henriquez M, Gallagher E, Morrison J, Austin JM, Scott TM, Senechal N (2010a) Mean Lagrangian flow behaviour on open coast rip channeled beaches. Mar Geol 268:1-15

MacMahan JH, Reniers AJHM, Thornton EB (2010b) Vortical surf zone fluctuations within 0(10) min period. J Geophys Res 115: C06007. doi:10.1029/2009JC005383

Masselink G, Short AD (1993) The effect of tide range on beach morphodynamics and morphology: a conceptual model. J Coast Res 9:785-800

Masselink G, Austin M, Tinker J, O'Hara J, Russell P (2008) Crossshore sediment transport and morphological response on a macrotidal beach with intertidal bar morphology, Truc Vert, France. Mar Geol 251:141-155

Masselink G, Russell PE, Turner IL, Blenkinsopp CE (2009) Net sediment transport and morphological change in the swash zone of a high-energy sandy beach from swash event to tidal cycle time scales. Mar Geol 267:18-35

Michallet H, Mory M, Piedra-Cueva I (2009) Wave-induced pore pressure measurements near a coastal structure. J Geophys Res 114:C06019. doi:10.1029/2008JC005071

Mignot E, Hurther D, Chassagneux F-X, Barnoud J-M (2009) A field study of the ripple vortex shedding process in the shoaling zone of a macro-tidal sandy beach. J Coast Res SI56: 1776-1780

Mory M, Michallet H, Bonjean D, Piedra-Cueva I, Barnoud J-M, Foray P, Abadie S, Breul P (2007) A field study of momentary liquefaction caused by saves around a coastal structure. J Waterw, Port, Coast Ocean Eng 133:28-38

Ngusaru AS, Hay AE (2004) Cross-shore migration of lunate megaripples during Duck94. J Geophys Res 109:C02006. doi:10.1029/2002JC001532

Noyes TJ, Guza RT, Elgar S, Herbers THC (2004) Field observations of shear waves in the surf zone. J Geophys Res 109:C01031. doi:10.1029/2002JC001761

Oltman-shay J, Guza RT (1987) Infragravity edge wave observations on two California beaches. J Phys Oceanogr 17(5):644-663
Oltman-Shay J, Howd PA, Birkemeier WA (1989) Shear instabilities of the mean longshore current 2. Field observations. J Geophys Res 94(C12):18031-18042

Parisot JP, Capo S, Castelle B, Bujan S, Moreau J, Gervais M, Réjas A, Hanquiez V, Almar R, Marieu V, Gaunet J, Gluard L, George I, Nahon A, Dehouck A, Certain R, Barthe P, Le Gall F, Bernardi PJ, Le Roy R, Pedreros R, Delattre M, Brillet J, Sénéchal N (2009) Evolution of a multi-barred sandy beaches in presence of very energetic events. J Coast Res SI56:17861790

Pawka SS (1983) Island shadows in wave directional spectra. J Geophys Res 88(C4):2579-2591

Plant NG, Freilich MH, Holman RA (2001) Role of morphologic feedback in surf zone sandbar response. J Geophys Res 106 (C1):973-989

Price TD, Ruessink BG (2008) Morphodynamic zone variability on a microtidal barred beach. Mar Geol 251:98-109

Quartel S, Ruessink BG, Kroon A (2007) Daily to seasonal crossshore behaviour of quasi-persistent intertidal beach morphology. Earth Surf Process Landf 32:1293-1307

Ranasinghe R, Symonds K, Holman R (2004) Morphodynamic of intermediate beaches: a video imaging and numerical modeling study. Coast Eng 51:629-655

Reichmüth B, Anthony EJ (2007) Tidal influence on the intertidal bar morphology of two contrasting macrotidal beaches. Geomorphology 90:101-114

Rejas A, Senechal N, Capo S, Parisot JP, MacMahan JHM, Bryan KR, Coco G (2009) Field and video observations of morphological change during a large-scale, multi-institutional experiment (ECORS). In: Proceedings of Australasian Coasts and Ports, Wellington, September 2009

Reniers Ad JHM, Roelvink JA, Thornton EB (2004) Morphodynamic modeling of an embayed beach under wave group forcing. J Geophys Res 109:C01030. doi:10.1029/2002JC001586

Reniers Ad JHM, MacMahan JHM, Thornton EB, Stanton TP (2006) Modelling infragravity motions on rip channel beach. Coast Eng 53:209-222

Reniers Ad JHM, MacMahan JHM, Thornton EB, Stanton TP (2007) Modeling of very low frequency motions during RIPEX. J Geophys Res. doi:10.1029/2005JC003122

Reniers Ad JHM, MacMahan JHM, Thornton EB, Stanton TP, Henriquez M, Brown JW, Brown JA, Gallagher E (2009) Surfzone surface retention on a rip channeled beach. J Geophys Res 114:C10010

Reniers Ad JHM, MacMahan JHM, Beron-Vera FJ, Olascoaga MJ (2010) Rip-current pulses tied to Lagrangian coherent structures. Geophys Res Lett 37:L05605. doi:10.1029/2009GL041443

Rubin DM (2004) A simple autocorrelation algorithm for determining grain size from digital images of sediment. J Sediment Res $74: 160-165$

Ruessink BG (2010) Observations of turbulence within a natural surf zone. J Phys Oceanogr 40(12):2696-2712

Ruessink BG, Kroon A (1994) The behaviour of a multiple bar system in the nearshore zone of Terschelling, the Netherlands: 19651993. Mar Geol 121:187-197

Ruessink BG, Houwman KT, Hoekstra P (1998) The systematic contribution of transporting mechanisms to the cross-shore sediment transport in water depths of 3 to $9 \mathrm{~m}$. Mar Geol 152:295-324

Ruessink BG, Miles JR, Feddersen F, Guza RT, Elgar S (2001) Modeling the alongshore current on barred beaches. J Geophys Res 106:22,451-22,463

Ruessink BG, Coco G, Ranasinghe R, Turner IL (2007) Coupled and noncoupled behaviour of three-dimensional morphological patterns in a double sandbar system. J Geophys Res 112:C07002. doi:10.1029/2006JC003799 
Ruggiero P, Komar PD, McDouglas WG, Marra JJ, Beach RA (2001) Wave runup, extreme water levels and erosion of properties backing beaches. J Coast Res 17(2):407-419

Russell PE, Masselink G, Blenkinsopp C, Turner IL (2009) A comparison of berm accretion in the swash zone on sand and gravel beaches at the timescale of individual waves. J Coast Res SI56:1791-1795

Ruz M-H, Hequette A, Maspataud A (2009) Identifying forcing conditions responsible for foredune erosion on the northern coast of France. J Coast Res SI56:356-360

Ryrie SC (1983) Longshore motion due to an obliquely incident wave group. J Fluid Mech 137:273-284

Saulter AN, Russell PE, Gallagher EL, Miles JR (2003) Observations of bed level change in a saturated surf zone. J Geophys Res 108 (C4):3112. doi:10.1029/2000JC000684

Schmidt WE, Guza RT, Slinn DN (2005) Surf zone currents over irregular bathymetry: drifter observations and numerical simulations. J Geophys Res 110:C12015. doi:10.1029/2004JC002421

Senechal N, Dupuis H, Bonneton P, Howa H, Pedreros R (2001) Observation of irregular wave transformation in the surf zone over a gently sloping sandy beach on the French Atlantic coastline. Oceanol Acta 24:545-556

Senechal N, Bonneton P, Dupuis H (2002) Field experiment on secondary wave generation on a barred beach and the consequent evolution of energy dissipation on the beach face. Coast Eng 46:233-247

Senechal N, Dupuis H, Bonneton P (2004) Preliminary hydrodynamic results of a field experiment on a barred beach, Truc Vert beach on October 2001. Ocean Dyn 54:408-414

Senechal N, Gouriou T, Castelle B, Parisot J-P, Capo S, Bujan S, Howa H (2009) Morphodynamic response of a meso macrotidal intermediate beach based on a long term data set. Geomorphology 107:263-274. doi:10.1016/j.geomorph.2008.12.016

Sénéchal N, Coco G, Bryan K, Holman RA (2011) Wave runup under extreme storm conditions. J Geophys Res Oceans. doi:10.1029/ 2010JC006814

Smit MWJ, Reniers AJHM, Ruessink BG, Roelvink JA (2008) The morphological response of a nearshore double sandbar system to constant wave forcing. Coast Eng 55:761-770

Spydell M, Feddersen F, Guza RT, Schmidt WE (2007) Observing surfzone dispersion with drifters. J Phys Oceanogr 37(12):2920-2939
Symonds G, Ranasinghe R (2000) On the formation of rip currents on a plane beach, ICCE, Sydney, Australia, ASCE, pp 468-481

Thomas S, Ridd PV (2004) Review of methods to measure short time scale sediment accumulation. Mar Geol 207(1-4):95-114

Thornton EB, Kim CS (1993) Longshore current and wave height modulation at tidal frequency inside the surf zone. J Geophys Res 98:16,509-16,520

Thornton EB, Humiston RT, Birkemeier W (1996) Bar/trough generation on a natural beach. J Geophys Res 101(C5):12,097-12,110

Thornton E, Dalrymple T, Drake T, Gallagher E, Guza B, Hay A, Holman R, Kaihatu J, Lippmann T, Ozkan-Haller T (2000) State of nearshore processes research: II. Technical Report NPS-OC00-001 Naval Postgraduate School, Monterey, California 93943

Thornton E, Mac Mahan JH, Sallenger AH Jr (2007) Rip currents, mega-cusps, and eroding dunes. Mar Geol 1-4:151-167

Tissier M, Bonneton P, Almar R, Castelle B, Bonneton N (2009) Field observations of wave celerity in the surf zone. In: Proc. 19th CFM Congress, France, $6 \mathrm{p}$

Turner IL, Nielsen P (1997) Rapid watertable fluctuations: implications for swash zone sediment mobility. Coast Eng $32: 45-59$

Turner IL, Whyte D, Ruessink BG, Ranasinghe R (2007) Observations of rip spacing, persistence and mobility at a long straight coastline. Mar Geol 236(3-4):209-221

Turner IL, Russell PE, Butt T (2008) Measurement of wave-by-wave bed-levels in the swash zone. Coast Eng 55:1237-1242

Turner IL, Russell PE, Butt T, Masselink G, Blenkinsopp CE (2009) In-situ estimates of net sediment flux per swash: reply to discussion by TE Baldock of "Measurement of wave-by-wave bed-levels in the swash zone. Coast Eng 56:1009-1012

Van Enckevort IMJ, Ruessink BG (2003a) Video observations of nearshore bar behaviour, part I: alongshore uniform variability. Cont Shelf Res 23:501-512

Van Enckevort IMJ, Ruessink G (2003b) Video observations of nearshore bar behaviour, part II: alongshore non-uniform variability. Cont Shelf Res 23:513-532

Weir FM, Hughes MG, Baldock TE (2006) Beachface and berm morphodynamics fronting a coastal lagoon. Geomorphology 82:331-346

Wright LD, Short AD (1984) Morphodynamic variability of surf zones and beaches: a synthesis. Mar Geol 56:93-118 